(Aus der orthopädisch-chisurgischen Ǩlinik der Universität zu Köln.

[Direktor: Professor Dr. C. ('ramer.])

\title{
Über progrediente Fußdeformitäten bei Spina bifida occulta.
}

\author{
Von \\ I)r. med. L. Roeren. \\ Assistenzarzt.
}

Mit $i$ Abbildungen im Text.

(Eingegangen im August 1920.)

Literatur.

1. Sa muel, S., Die trophischen Nerven. Leipzig 1860. - 2. Cassirer, R., Die vasomotorisch-trophischen Neurosen. Berlin 1912. Angeführt bei Iandois-Rosemann, Lehrb. d. Phys. 15. Aufl. 1919. - 3. Mackenzic, James, Krankheitszeichen und ihre Auslegung. Würzburg 1917. - 4. Vulpius, Zur Ätiologie des angeborenen Klumpfußes. 1. Kongreß. Verhandl. d. deutsch. Gesellsch. f. Orthop 1902. - 5. Fischer, Virchows Archiv 105, 1886. - 6. v. Recklinghausen, Ebenda. ‥ 7. Brunner, Ebenda 107 u. 129. - 8. Le bedeff, Ebenda 36. - 9. Ribbert, Ebenda 139. - 160. Bohns ted t, Ebenda 140. - 11. v. Bergmann, Berl. klin. Wochenschr. 1884. - 12. Henneberg, Ebenda 1919. Nr. 49. 1173. - 13. Duchenne, Physiologie der Bewegungen. 1885. - 14. Ernst, MiB. bildungen des Nervensystems (aus Schwalbe, Die Morphologie der Mißbildungen des Menschen und der Tiere. 1909). - 15. Gudden, Arch. f. Psychiatrie 30. - 16. de Quervain, Gesellschaft der Arzte Basel. Dezember 1911. - 17. Pe ritz. Deutsche med. Wochenschr. 1911. Nr. 27. - 18. Maa 3 , Fbenda 1897. Nr. 47. - 19. Beck, Spina bif. oce. und angeb. Klumpfuß. Münch. med. Wochenschr. 1920. Nr. 11. - 20. Peltesohn, Ebenda 1919. Nr.47. 21. Nicoladoni, Über den Pes calcaneus. Arch. f. klin. Chir. 26, II. - 22. Wolff, I., Uher die Ursachen, das Wesen und die Behandlung des Klumpfußes. - 23. Villiger, E., 1)ie periphere Innervation. Leipzig 1919. - 24. Fischer, O., Kinematik organischer Cielenke. 1907. - 25. Fick, Handbuch der Anatomie und Mechanik der Gelenke. 26. Spalteholz, Handatlas der Anatomie des Menschen. 1907. - 27. Müller, Ernst, Tentralb. f. Chir. 1903. Nr. 2. - 28. Bing, Kompendium der topischen Gehirn- tund Rückenmarksdiagnostik. 1919. - 29. Edinger, L., Einführung in die Lehre vom Bau und den Verrichtungen des Nervens. 1912. - 30. StraBer, Lehrbuch der Muskel- und Gelenkmechanik. III. Teil. 1917. - M. Cra mer, K., Arch. f. Orthop., Mechanotherap. u. Unfall. chirurgie 12, 1913. -- 32. Roux, Abhandlungen über Entwicklungsmechanik. 1895. … 33. Bickel, Uber die Umbahnung usw. Minch. med. Wochenschr. 1920. Nr. 27. 34. Schulthe B, Verbandl. d. deutsch. Gesellsch. f. orthop. Chir. 1912. - 35. Ja min, E., Experimentelle Untersuchungen zur Lehre von der Atrophie gelähmter Muskeln. Jena 1904. - 36. Biesalski-Mayer, Die physiologische Sehnenverpflanzung. 1916. - 37. Bartels, Archiv für Anthropologie 1881 usw., angef. bei v. Bergmann. -- 38. Virchow, 
Zeitschrift für Ethnologie 7. 1875. - 39. Borst, Ergebnisse der allgemeinen Pathologie. - 40. Cathelin. Fpiruralinjektionen. Stuttgart 1903. - 41. Heubner, Lehrbuch der Kinderheilkunde 2 (Cathelin und Heubner bei Peritz). - 42. v. Mering, J., Lehrbuch der inneren Medizin. 1911. - 43. Hoffa, Lehrbuch der orthopädischen Chirureie. 190.5. - 44. Denucé. M., La Pratique des maladies des enfants. 8, 1913, - 45. Stratz, Der Körper des Kindes.

Ferner aus der Zeitschrift für orthopädische Chirurgie:

1. Hübscher, Die Atrophie des Flex. h. l. beim Plattfuß. 17. - 2. Engels, Über den normalen Fuß und den Plattfuß. 12. - 3. Giani, Die Funktion des M. t. ant. usw. 14. - 4. Saxl, Ebenda. Der trans. paral. KlumpfuB. -.. 5. Frä́nkel, Ehenda. Uber den Fuß der Chinesinnen. - 6. Duncker, Der Klauenhohlfuß und verw. usw. 33. - 7. Bibergeil, Ebenda. Die Beziehungen der Spina bifida occulta usw. -- 8. Fränkel, Zur Ätiologie und Therapie des angeborenen Klumpfußes. 32. - 9. Fränkel, Die infantile zerebrale Hemiplegie. 15. - 10. Cramer, K., Uther Operationsbefunde usw. 13 (KongreB). 11. Kruckenberg, ther operationslose Behandlung usw. 13 (KongreB). - 12. Joachimstal, Die angeborene Hüftverrenkung usw. 29. - 13. Meyer, M., Uber multiple usw. $\mathbf{2 2 .}$ - 14. Guérin.Valmale et Jeanbran, Dissection d'une main-bote cubitale pure avec luxation congénitale du conde. Bei Meyer. -- 15. Hoh mann, Zur Ätiologie und Pathologie nsw. 19. - 16. Ewald, Úber den Knick- und den Plattfuß. 25. - 17. Rosenfeld, Die idiopathische Innenrotation usw. 25. - 18. Bardenheue r, Der stat. Pes valgus usw. 96. - 19. Hase broek, Utber schlechte Haltung usw. 26. - 20. Tu rner. Uber die Beziehung usw. 27. - 21. Pürckhauer, Zur Pathologie und Therapie usw. 30. - 22. Duncker, Pes adductus. 30.

„Wenn man in einem gegebenen Fall nach der Ursache einer Gruppe von Symptomen sucht - mögen sie räumlich auch weit auseinander liegen und in ihrem Wesen sich sehr unterscheiden -, so wird man viel wahrscheinlicher den Zusammenhang auffinden durch die Annahme einer einheitlichen Grundlage der ganzen Symptomengruppe als durch die Annahme einer Mehrheit von Ursachen. Diese Methode, bei den Logikern: Das Gesetz cler Sparsamkeit in Hypothesen genannt, sollte stets streng befolgt werden, und wenu sie auch nicht immer erfolgreich ist, so wird doch das Suchen nach einom Zusammenhang zwischen den verschiedenen Phünomenen viele, vorläufig übersehene oder vernachlässigte Tatsachen offenbaren und einen guten Führer für die weitere Forschung ahgeben. Geeignete Objekte für die Anwendung dieses Gesetzes sind die Untersuchungen von Herderkrankungen des Gehirnes oder Rückenmarks. Krankheitsherde von geringer Ausdehnung können in diesen O rganen weit auseinander liegende Symptome hervorrufen, wie Lähmungen in einem Teil des Körpers und Gefühlsstörungen in einem anderen oder auch gestörte Funktionen in gewissen Eingeweiden."

Diese Thesen des englischen Forschers James Mackenzie scheinen mir außerordentlich beherzigenswert. Ihre Richtigkeit gibt der vorliegenclen Arbeit - trotz der Zeit des ,Vielschreibens" - ein Daseinsrecht insofern. als in derselben versucht werden soll, eine gewisse Anzahl ron Erscheinungen, die bisher in mannigfachen Spezialarbeiten oft verschiedene Deutung insbesondere hinsichtlich ihrer Ätiologie erfahren haben, unter einer Einheitlichkeit zusammenzufassen und dadurch uns einem klareren ( $k$ lar gleich einfach) Begriff der in der Utberschrift erwähnten Symptomvereinigung näher zu bringen.

Die Gelegenheit, auf der großen Militärstation und auf der orthopädischen Klinik sowie Poliklinik im Laufe des letzten Jahres in gehäufter Anzahl Erkrankungen bezeichneter Art zu beobachten, gab Professor Craner Ver- 
anlassung, von neuem zur Bearbeitung dieses noch nicht geklärten Gebietes anzuregen. Die Zahl der untersuchten Fälle ist mit 40 sicher nicht zu boch angegeben. Eine zahlenmäßige Statistik konnte aus technischen Gründen leider nicht durchgeführt werden (ist auch meines Erachtens unwesentlich) und aus dem gleichen Grunde - Massenandrang der „Kriegsbeschädigten“ konnte bedauerlicherweise die Befunderhebung nicht immer genügend ausführlich fixiert werden. Ich beschränke mich in meiner Arbeit daher im wesent. lichen auf die stationär behandelten Fälle und erwähne andere nur, wenn sie in ihrem Bilde bedeutungsvolle Eigenarten aufwiesen, die selbstverständlich niedergelegt wurden.

In Band 33 der Zeitschrift für orthopädische Chir.urgie sind zwei längere Arbeiten über das gleiche Thema erschienen, von denen die eine ebenfalls aus der hiesigen Klinik hervorging. In beiden Abhandlungen wird in positiver Weise ein Zusammenhang der Fußdeformität mit einer Wirbelspalte als Kausa und Effekt dargestellt und zu erklären versucht. Duncker betont dieses schon in der Uberschrift: Der Klauenhohlfuß und verwandte progressive Deformitäten als Folgeerscheinungen von Spina bifida occulta, während Bibergeil in seiner Arbeit sagt: „Trotz der zahlreichen Beziehungen, die somit zwischen der Spina bifida occulta und dem Hohlfuß bestehen, kann ihr doch nicht unter allen Umständen eine direkte ätiologische Bedeutung für eine sich ausbildende Fußdeformität zugesprochen werden." Beide versuchen, das Nebeneinander dieser zwei Symptomenkomplexe in ein Kausalverhältnis zueinander zu bringen, und darin liegt die Bedeutung ihrer Schriften, denn sie weisen dadurch den Weg einer Therapie, die nicht vielleicht rein symptomatisch, sondern spezifisch ist. Aber auch schon in der älteren Literatur finden sich ganz analoge Auffassungen des in Frage stehenden Krankheitsbildeg; so konnte $J$ ones (angeführt bei Geiges) im Jahre 1891 durch Entfernung eines breiten fibrösen Bandes aus dem Sakralkanal bei Spina bifida occulta vorher bestehende Iähmungserscheinungen zum Schwinden bringen. Ganz ähnlich beseitigte Katzenstein (bei Peritz) eine Strangbildung und sah nachfolgend Heilung paralytischer Symptome. Derartiger Beispiele lassen sich noch mehr anführen; ich will nur noch einen Autor zitieren, weil ebenso hier wie in den Arbeiten von Duncker und Bibergeil gesagt wird, wie man sich die Abhängigkeit der Fußmißbildung von der Störung in Rücken dachte. D e n u c é schreibt. ,,Le spina bidifa occulta peut s'accompagner, tardivement, de troubles moteurs, sensibles et trophiques. Chez des enfants on même des adolescents qui jusque-lá avaient paru normaux, on voit survenir peu à peu des phénomènes paralytiques . . assez exceptionellement des troubles d'anesthésie ou des phénomènes névralgiques .. Dans certains cas, on voit aussi, tardivement, survenir de l'incontinence... Dans les cas de spina bifida occlusa, comme dans le spina bifida occulta, on peut voir, tardivement, survenir des troubles de compression, moteurs, sensibles ou trophiques..." Und erwähnt bei der Therapie: ,.. . . pour ce qui concerne le spina bifida occulta, s'il ne donne lieu à aucun symptôme gênant, il n'y a évidemment aucune raison, d'intervenir. Ce n'est guère que s'il survient une paralysie tardive qu'on pensera ì une intervention . . . elle (la paralysie) peut etre en effet la conséquence d'une compression survenue d'occlusion; l'incision ou l'extirpation d'une 
tumeur sus ou sous-jacente a la membrane d'occlusion, l'incision on l'extirpation de cette membrane ont donné des cas de guérison." Aus der Art der Therapie ergibt sich, daß D e n u e é als das Primäre eine Sichüdigung des Rïckenmarks durch Tumorendruck oder Zerrung infolge Verwachsungen ansah und die Fußdeformität erst hierdurch bedingt wurde; rlenn sonst wïrde sein Vorschlag unbegrïndet, wenn nicht sinnlos erscheinen. Analoge Auffassung des Krankheitsbildes ergibt sich aus den in der Dunckerschen Arbeit angefïhrten Operationen. Duncker entfernte Jipome, Narbenstränge, löste Verwachsungen und fand in bindegewebig durchflochtenen lipomatösen Massen einzelne stark gequollene Nervenwurzeln; doch wohl mur, weil er eine Schärligung des Marks rlurch diese Tumoren in gleicher Weise wie bei anderen Neubildungen vorausetyte. Aber Duncker geht noch weiter. Aus den an Wirbeliäule und Dura gefundenen Defektbildungen macht er einen Riickschluß auf ain ,.Vitimm primae formationis" auch für das Rückenmark; hält jedoch selbst diese knngenitale Myelodysplasie mit eventuell anch Abschnürung und sekundiirer Statung der Nervenwurzeln nicht als hinreichend, $11 \mathrm{~m}$ das Zustandekommen der Deformitäten zu erklären. Der oft späte Beginn, die langsame Progredienz. und die häufige Einseitigkeit erfordern noch ein anderes, und als solches spielen naeh Duncker ,differente Entwicklungstendenzen des dysplastischen und des normalen Gewebes, sowie mechanische Behinderung des physiologischen Aufsteigens der Medulla... während des allgemeinen Körperwachstums eine nicht unwesentliche Rolle." Zurückhaltender noch jst Bibergeil, nach welchem die Entwicklung der Deformitn̈t zwar eng mit den Fntwicklungsstörungen an Wirbelsäule und Rückenmark verknïpt ist, aher keine neue kausale Therapie erkennen läßt, solange.man nicht weiß, ,in welcher Weise das Rückenmark durch die Wirheldehiszenz in seiner Funktion gestört wird". Nur in Fällen manifester Drucklähmung ist für ihn der therapentische Weg gegeben. Ich glaube, daß nach dieser Einschränkung Bibergejls der operative Eingriff an der Wirbelsäule fast ganz hinfällig würde; denn bis wir hei dem Bilde der Spina bifida occulta verbunden mit progredienter Fußdeformität einer als solcher sicher und zweifelsf rei zu diagnostizierenden Drucklähmung begegnen würden, dürften wir wohl ein gewaltiges Material durch. sieben müssen. Unter den hier beobachteten Fullen war kein einziger, der in eindeutiger Weise das Bild eines das Rückenmark drückenden und schädigenden. Tumors gezeigt hätte.

Beide Autoren fühlen das Cnzulängliche der Annahme einer - fast wöchte ich sagen rein mechanischen - fortschreitenden Schädigung des Markes durch den Druck eines Tumors zur Deutung und Erklärung der progredienten Fußdeformität. Es muß noch ein anderes hinzutreten, das im Mark selbst zu suchen ist. Nach Duncker sind es Wachstumsunterschiede zwischen dem gesunilen und dem kranken Gewebe und - seltsamerweise ein rein mechanisches Moment, - die Behinderung des Emporsteigens der Medulla. Dieses letztere ist, wie ich später zeigen werde, einer Schädligung des Marks durch einen Tumor ziemlich gleichwertig zu setzen, kann also auch nicht sehr zur Erweiterung der Dunckerschen Erklärung beitragen. Es bleibt nur die in beiden Arbeiten nicht näher besproshene Schädigung übrig, die das Mark selbst infolge der MiBbildung getroffen hat. Der Erfolg des operativen Eingriffs am Markkinal, 
der rum mal in vielen Fiallen einwandfrei fextgestellt werden konnte (Literatur und eigene Beobachtung), läßt ja eigentlich das Suchen nach anderen, die FuBbildung beeinflussenden Momenten überflïssig erseheinen; denn er wird durch Hinzutreten weiterer Schäden am Mark in seiner Berleutung und Wichtigkeit herabgesetzt. Aber das klinische Bild der Krankheit mit ihrem so verschiedenen zeitlichen Beginn, mit ihrer langsamen Progredienz und dem of $t$ einseitigen Auftreten and vor allem die hier gemachte Beobachtung, da $\beta$ bei selbst hochgradigen Verunstaltungen eines Fußes die extraduralen Verhältnisse im untersten Markkanal sich röllig normal erwiesen (keine Fettgeschwulst, keine fibrösen Strünge usw.), zwingen zur Annahme noch anderer pathologischer Vorgänge, die sich im Mark, in den Nerven oder in der Muskulatur abspielen müssen. Schädigung durch Tumoren oder Verwachsungen von außen her -... anf der einen Snite --- und krankhafte Vorgänge im Innern des Markes selbst, in den Nerven und in der Muskulatur - auf der anderen Seite - sind die beiden Punkte, deren richtige wertige Ahgrenzung zueinander im folgenden versucht werdell soll. Sie wird uns gleichzeitig eine Klä rung unseres Symptomenkomplexes bringen und der Therapie Wege denten, die neben den symptomatischen auch einen kausalen Heilerfolg versprechen.

In der jüngsten dieses Gebiet berïhrenden Arlyeit von Beck (der zweite l'eil liegt hier bis zur Stunde noch nicht vor) wird der zu Rezidiven neigende angeborene Klumpfuls mit der verborgenen Wirbelspalte in Zusammenhang gebracht. Beck erwïhnt ganz allgemęin die von anderen Forschern wie $\mathrm{Rib}$ be $\mathrm{r} t$, $\therefore$ Recklinghausen, Bonnstedt, Klebs, Bland Sutton festgestellten Veründerungen an Mark und peripheren Nerven: intradural gelegene Tumoren, bis in höhere Abschnitte hinaufreichende Dysplasien. Sklerosierungen, Defekte an austretenden Nervenwurzeln, degenerative Veränderungen an den peripheren Nerven usw. und schließst dann weiter: .Wenden wir diese Tatsachen auf den angeborenen Klumpfuß un, so erklärt uns die Spina bifida occulta, daß infolge der trophischen Störung der Fuß, hin und wieder sogar das ganze Bein in Wachstum zurückbleibt, daß für immer eine Atrophie der Wadenmuskulatur und eine Schwäche in der Peronealmuskulatur resultiert. Wir können ferner verstehen, daß der Talus sich nicht gleichruäßig entwickelt, sondern an der lateralen Seite ein stärkeres Wachstum zeigt als an der medialen. sodaß eine laterale Konvexität des Talushalses sich ausbildet. Und wir haben somit, da der Talus der am meisten geschädigte Knochen beim Pes varus congenitus ist, eine Erklärung für die Adduktion, Supination und die Hohlfußbildung beim Klumpfuß . . .. Diese Schlußfolgerungen, so wie sie einem in der vorliegenden Arbeit geboten werden, sind in dieser Form durchaus unbefriedigend, vielleicht bringt der zweite Teil näheren Aufschluß. Es bleiben Fragen offen wie zum Beispiel: Warum ist gerade clie Peronealnuskulatur geschwächt? Warum wächst der Talus an der lateralen Seite lebhafter, so dảß der Fuß in Adduktion, Supination und Hohlfußstellung treten soll? u. a. m. $\checkmark$ ielleicht kann man sich denken, daß in den Fällen des sogenannten rebellischen Klumpfußes die Störungen in Mark und Nerven gerade so lokalisiert sind, daß vornehmlich die Peronïen (deren Bedeutung für die Fußstellung übrigens noch genauer zu präzisieren ist) geschwächt sind, und daß vornehmlich die Jaterale Seite des Talus stärkere Wachstumsreize zugeführt bekommt . . . 
würde die Störung andere Nervenzweige und andere Markgebiete gretroffen haben, so würde auch eine andere Fußmißbilkung daraus resultieren . . . Eine Lösung, die durch die Schlußbemerkungen des Verfassers nahe gelegt wird, wenn er Fälle von Hohlfüßen und von hartnäckigen Plattfüßen mit Spina bifida occulta in Verbindung bringt. Wie weit meine Annahme richtig ist, wird wohl die angekündigte ausführliche Arbeit zeigen. Es ist daher müßig, jetzt darüber zu streiten. Nur auf eines möchte ich cloch aufmerksam machen: In welcher Art soll das einseitige Wachstum des Talus von der Störung an Mark und Nerven abhängig sein, so daß bei nervöser Schwächung der Peronäen ein laterales Wachstum überwiegt, während doch beim Plattfuß der Talus in ganz anderer Weise seine äußere Form verändert? Soll auch hier der geschädigte Knochen des Talus analog wie bein Pes varus congenitus eine Erklärung abgeben für die Abduktion, Pronation und Abflachung bein Pes planus? Und das als primär wirkende Ursache? Fragen wir die Physiologen, so sagen sie uns, daß die Annahme einer direkten Beeinflussung des Stoffwechsels und des Wachstums der Gewebe durch das Zentralnervensystem zum mindesten zweifelhaft ist; denn sogenannte trophische Störungen können durch die Einflüsse der sensiblen, motorischen und vasomotorischen Nervenfasern zur Genüge erklärt werden. Es klingt doch mehr als unwahrscheinlich, anzunehmen, da $B$ etwa beim Klumpfuß die Vasomotoren die laterale Seite des Talus besser versorgten als die mediale . . ., beim Plattfuß jedoch wieder in ganz anderer Art . . . und daß dieses auf einen Reiz von oben her erfolge! Und sind wirklich rein trophische Nerven vorhanden, die vom Zentralnervensystem zum Talus hinziehen, so gilt ebenfalls das oben Gesagte: denn es ist nicht anzunehmen, daß das Ursprungsgebiet der trophischen Nerven für einen einzelnen Knochen ein großes, ausgedehntes sei, so daß nun gerade hänfig die Ursprungszone der Fasern zur lateralen Hälfte, wie sie das nicht seltene Vorkommen des kongenitalen Klumpfußes erheischen würde, in bestimmter Weise leistungsfähiger sein soll als die der zur medialen Seite hinziehenden Fasern! Bei der spinalen Kinderlähmung mit ihren oft recht ausgedehnten vasomotorischen Störungen werden etwa auftretende Fußverbildungen nicht auf diese, sondern auf die gestörte Funktion zurückgeführt. Knochenveränderungen bei tabischen Gelenken und bei der Syringomyelie lassen sich zum größten Teil durch das Fehlen der Sensibilität und dadurch bedingte übermäßige, regelwidrige und gar direkt schäcligende Inanspruchnahme der Gelenke und Gliedmaßen erklären. Das Wachstum hängt in erster Linie ab ,,von dem Wachstumstrieb, einer vererbten Eigenschaft der Zellen" (Rose mann). Die Muskeln zun Beispiel wachsen in der Embryonalperiode dur'ch Selbstdifferenzierung und in der postembryonalen Periode des funktionellen Reizlebens sind Wachstum und Entwicklung von funktionellen, und zwar hier motorischen, Reizen abhängig (Ernst, Roux). Ich will nun nicht die Existenz rein trophischer Nervenfasern als ein leeres Phantasiegebilde darstellen, sondern nur betonen, daß an der Regelung des Wachstums und der Formung der Körpergewebe auch andere Faktoren mächtigen Anteil haben und hier nicht zum wenigsten funktionelle Reize and solche, die von außen her erst zentripetal einströmen, dann umgeformt werden und nun zentrifugal (vielleicht auf den Bahnen rein trophischer Nerven oder vasomotorischer) auf Wachstum und Formung auch peripherster Körperteile 
Einfluß gewimnen. Bei dem unermeßlichen Reichtum an Nervenfasern. treten doch nach neweren Forschungen an jede einzelne Epithelzelle eine oder gar mehrere Nervenfusern herin und sind Sehnen und Muskelfasern von einem förmlichen Nervengespinnst umbïllt (Edinger), ist das Vorhandensein spezifischer Nervenfasern für die Regehung des Wachstums, wenu auch nicht erwiesen, so doch sehr wahrscheinlich; aber auch diese sind vielfach abhängig von zentripetal einlaufenden Reizen: Druck, Belastung, Zug, Temperatur usw. Es ist ein Vorgang in der Art der Reflexbewegungen. Ein Beispiel möge das er'ïutern : Eine Hautstelle am Fuß wird durch irgendwelche Umstände in sonst nicht gewohnter Weise durch Belastung beim Gehen einem regelmäßig wiederkehrenden Druck ausgesetzt. Durch die zentripetalleitenden Bahnen teilt sich clieser anormale Reiz, dem die Haut in ihrer jetzigen Beschaffenheit auf die Daner nicht gewachsen wïre, einem zentralen Sitze zu und von diesem aus werden dann auf den oben beschriebenen Wegen durch zentrifugale Nervenfasem in der betroffenen Haut Vorginge ausgelöst, die einer drohenden Schïdigung vorbeugen und die Haut der neuen Funktion ampassen sollen. Halten diese Abwehrmaßregeln etwa infolge von Hemmungen, die in clem, .nutritiven“" Reflexbogen ihren sitz haben oder aber weil die Reize iibermïßig stark sind. den kurch diese Reize bedingten Schüdigungen nicht stand, so kommt es zur Drucknelsrose, anderenfalls tritt in Anpussung an die veränderte Funktion Verlickung, vielleicht sogar Verschwielung der Haut ein. So könnte man sich den Vorgang der langsamen Verdickung und Verhärtung der Fußsohlenhaut beim Kinde, das Gehen lernt. erklären. Entzündliche Prozesse, die beim kleinen Läufling ja nich t auftreten. sonst aber wohl häufiger bei abnormer Beanspruchung der Haut gegen Druck beobachtet werden und dann auch zu einer Verdickung führen. wïrden demnach so zu bewerten sein, daß zunïchst ein Mißverhältnis bestand zwischen zentripetal einlaufendem Reiz und dadurch aungelöstem nutritiven Reflexvorgang, so daß es zur Schädigung der Haut kam. In diese geschädigte Haut nun konnten pathogene Keime eindringen, die clann ihrerseits einen zentripetalen Reiz bedingten, der in erhöhtem Maße den Abwehrapparat in Tätigkeit setzte. So würde man sich die Wachstumsregulierung durch das Zentralnervensystem vorstellen können, wenn man nicht den Vorgang des Wachsens und seine Umgrenzung in die lebende Zelle allein verlegt wissen will, so daß clie Reaktionen an Ort und Stelle durch vitale Eigenschaften des Protoplasmas begründet werden. Wahrscheinlich geht beides Hand in Hand. Es war mir nur darum zu tun, die Abhängigkeit des Wachstums von äußeren Einflüssen namentlich der Funktion auch dann als wirksam zu zeigen, wenn zentrale Kontrolle das Wachstum beherrscht.

Ich verweile bei dieser Frage nach der zentral bedingten Wachstumsstörung im Knochen deshalb länger, weil von manchen Seiten die Skelettveründerungen als etwas Primäres oder doch selbstïndig Nebenhergehendes angegeben werden; während ich sie bei den ,.progredienten Fußdeformitäten usw.: als sekundäre Folgeerscheinung aufasse. Die von Beck angeschuldigten trophischen Störungen im Bein sind für das Zustandekommen der Deformitäten gar nicht so hoch zu bewerten. Sensible und vasomotorische Störungen, in deren Gesellschaft sich meist die trophischen Stigmata finden, fehlen bei den zur Diskussion stehenden Mißbillungen meist ganz. Es bleibt 
also für die objektiv oft nachweisbare "Atrophie" in erster Linie die Störung in motorischen Nervenfasern als Hauptfaktor bestehen. Uber ihr Wesen wirl an weiterer stelle berichtet werden.

Fassen wir das bisher Gesagte zusammen, so zeigt es sich, daß in den neueren einschlägigen Arbeiten clie progrediente Fußdeformität, die mit einer Spina bifida occulta vergesellschaftet ist und durch irgendeine andere Krankheit wie Poliomyelitis anterioc, Syringomyelie, Friedreichsche Tabes usw. nicht bedingt wird, mit eben jener verborgenen Wirbelspalte in einen Kausalkonex gebracht wird. Nicht jedoch ist restlos erklärt. wieso es zu einer Fußverbildung kommt und vor allen Dingen nicht, warum die Umgestaltung mal früher, mal später erst in Erscheinung tritt und einen langsam progredienten Verlauf hat. Wenn ein Fuß das eine Mal eine im sechsten Lebensjahr beginnende, iiber Dezennien fortschreitencle Verkrüppelung aufweist, das andere Mal erst von etwa dem siebzehnten Lebensjahr an sich langsam umbildet, so gibt dafïr die clieses Moment am meisten berïcksichtigende Anschaunng in der Duncke $\mathrm{r}$ schen Arbeit meiner Ansicht nach auch nur eine unbefriedigende Erklärung. Wir mïssen also noch nach anderen Ursachen forschen, die insbesondere den chronischen Verlauf der Erscheinungen an den unteren Extremitäten bewirken.

Es scheint nun zweckmäßig, sich über die Veränderungen, die sich bei Spind bifida occulta am Markbanal und am Mark selbst vorfinden, genawer zu informieren und dabei auch die Frage nach der Entstehungsursache, -zeit und -art zu erörtern. Letzteres ist aber ein Gebiet, das zu erschöpfen, ein Studium für sich erforderte. Solches würde weit über den Rahmen dieser Arbeit hinausfallen. Ich beschränke mich daher auf einige Daten; denn wir werden später sehen, daß diese vollständig hinreichend sind, einen richtigen Weg zur Erklärung des Krankheitsbildes zu finden und daraus auch wichtige Richtungslinien für eine zweckmäßige Therapie zu fixieren.

Das Bild der Spina bifida occulta ist das Resultat einer Entwicklungsstörung. Daran wird wohl nicht zu zweifeln sein. Sie ist eine Stufe der durch Hemmung des normalen Schlusses der Medullarrinne zum Medullarrohr bedingten Folgeerscheinungen, deren höchster Grad in der totalen Rachischisis sich präsentiert und deren leichteste Folgen sich nur noch mikroskopisch an Rückenmarksquerschnitten nachweisen lassen, aber doch vielleicht eine Rolle spielen in der mitunter ungleichen Entwicklung der unteren Extremitäten. Der Abschluß3 der Medullarrinne zum Medullarrohr, die vollständige Loslösung derselben von der Körperoberfläche des Embryo, der Versehluß dieser Rückenmarksspalte und ihre Uberdeckung mit Haut muß normalerweise in clen ersten Lebenswochen vollendet sein. In dieser frühen und kurzen Zeit spielt sich also der zum späteren Bilde einer Spina bifida occulta führende Proze $\beta$ ab. Alles, was weiter kommt, sind Folgeerscheinungen dieser primären Entwicklungshemmung. Damit soll nicht gesagt sein, daß nicht auch ,gleichwertige"; aber anders lokalisierte Bildungsstörungen bei demselben Embryo vorhanden sein können. die mit der Schädigung im Rücken parallel gehen. Dahin gehören andere kongenitale Defekte (wie unter Umständen Hüftluxationen, Knochendefekte usw.), die mit einer Spina bifida occulta vereint nicht als Folge dieser, sondern als selbständig anzusehen sind. Eine vielleicht fehlerhafte Keimanlage hat sowohl erstere wie letztere bedingt. Es kann allerdings mitunter auch 
zweifelhaft sein, ob die beiclen kongenitalen Mißbildungen (z. B. kongenitaler Klumpfuß und Spina bifida occulta) gleicher Ordnung sind oder ob nicht im angeführten Beispiel der Klumpfuß der Spina bifida occulta untergeordnet, d. h. erst von ihr bedingt ist. Ein Klumpfuß kann unabhängig von einer gleichzeitig bestehenden Spina bifida occulta ebenfalls durch falsche Keimanlage (Hohmann u. a.) als Krankheitsbild sui generis oder durch die vielfach beschuldigte intrauterine Raumbeschränkung (Turner, Hippokrates, A mbroise Par'é u. a.) sich zu ersterer hinzugesellen. Auf der anderen Seite kann pr auch als Folge der Störung im Mark, einzig durch diese beding ‘, mit zur Welt gebracht werden.

Je geringer die Störung in. Mark und an der Wirbelsäule ist, um so weniger deutlich wird aus ihnen eruiert werden können, welche Teile vornehmlich bej dem mangelhaften Schluß des Medullarrohres in Mitleidensehaft gezogen werden. Das wird uns klarer, wenn wir die Schädigungen bei dem höchsten Grade des Defektes, bei einer totalen oder auch partiellen Rachischisis betrachten. In diesen Fällen findet man als Rest der Markanlage ein samtartiges Lager, zwischen den dicht durcheinander sich schlingenden Gefäßen liegen zerstreut Gliafasern. Glianetze und Gliazellen, daneben spärliche, gruppenweise angeordnete Ganglienzellen, die meist ohne Fortsätze sind (Emst). Von gewisser Bedeutung ist cler Umstand, daß irgendwelche Zeichen für erst gebildetes und dann aber wieder untergegangenes Nervengewebe sich nicht feststellen lassen. Was nicht da ist, wurde von vorneherein nicht angelegt und ist nicht erst durch eine von außen herantretende Noxe der Vernichtung preisgegeben worden. Die Gefäße, die immerhin eine gewisse typische Anordnung erkennen lassen, können nach Ernst nicht als angiomatöse Wucherungen aufgefaßt werden. Wir haben eine reine Defektbildung ror uns. Eine Art äberdauernder Medullarplatte.

Nun findet sich aber, und das scheint mir für die Lösung der in Abhandlung stehenden Fragen von besonderer Bedeutung, auch bej totaler Amyelie, daß sympathische Ganglien, Spinalganglien und hintere Wurzeln intakt sind. Ein Beweis für ,die weitgehende entwicklungsgeschichtliche Selbständigkeit der Ganglienanlagen und ihrer Produkte, der auswachsenden hinteren Wurzeln und ihrer Unabhängigkeit vom Medullarrohr.. Dies deckt sich mit der Auffassung von $H$ is, daß sich vor Abschluß des Medullarrohres die sympathischen und Spinalganglien als sogenannte Neuralleiste von der Medullarplatte abtrennen und neben die Wirbelsaule lagern. Und weiter noch stellte Erns t fest, daß sich die quergestreifte Muskulatur, obwohl die motorischen nervösen Elemente wie Vorderhornzellen und vordere Rüickenmarkswurzeln fehlten, normal und gut entwickelt hatte. Der Wachstumstrieb ist somit eine spezifische. vererbte Eigenschaft der Zelle also hier der quergestreiften Muskelfaser, die im Embryonalleben aus sich heraus wächst und erst im späteren Leben eines funktionellen (motorischen) Reizes bedarf, um vor Sobädigungen durch Fehlen dieses Reizes in der postembryonalen Periode, wie sie durch Tatsachen in der Pathologie in reichem Maße bewiesen werden, bewahrt zu bleiben (Roux, Landois-Rosemann, Ernst).

So ist das Bild bei den höchsten Graden der Markdefekte. Erreicht aber die Entwicklung des Rückenmarks einen höheren Reifegrad. so wird die sensible Komponente (die Ursprungskerne der sensiblen Fasern sind, wie aus dem oben 
Gesagten erhellt, in den Spinalganglien - für das periphere Neuron - und nicht im Zentralnervensystem zu suchen) sicher am ehesten diesen oder jenen Punkt ihrer zentral gelegenen, ZZiele:: zu denen auch die Vermittlung des Gefühles gehört, erreichen. falls nur das Rückenmark als durchgehender Strang angelegt ist, mögen auch innerer Aufbau und äußere Form noch von der Norm abweichen. (Näheres über das ,.Hinterwurzelsystem" wird weiter unten zu erwähnen sein.) In den leichtesten Formen unserer Mißbildung kommt es ¿ußßerlich zu der Eirscheinung der Spina bifida oceulta oder schließlich sogar zu der Spina bifida occlusa, bei der auch eine Wirbelspalte röntgenologisch nicht mehr festzustellen ist (Denucé u. a.). In allen diesen Fällen muß aber als das Wesen der Krankheit ein mehr oder minder hoher Grad einer Myelodysplasie (Fuchs, Duncker u. a.) vorhanden sein, und wegen der großen Selbständigkeit der Spinalganglien mit den hinteren Wurzeln, d. i. der gesamte zen tripetal leitende Apparat, muß sich die dureh diese Myelodysplasie bedingte störung in erster Linie an der motorischen Komponente dokumentieren. So viel über Entstehungszeit und Art der Mißbildung und über die Bedeutung dieser Fakta. Wir kommen nun zur Beschreibung und Bewertung der am Lebenden sich zeigenden pathologischen Veränderungen.

Berichte über Befunde bei den geringen und geringsten Graden der Rachischisis finden sich in der Literatur nur sehr wenig. Das liegt in der Natur rer Sache: das normale Verhalten der Wirbelsiule und der sie deckenden Haut bei oberflächlicher Betrachtung hat eben nie Veranlassung gegeben, hier nachzusehen; die Erkenntnis der Bedeutung dieser Mißbildung, die so gerne mit einer Fußdeformität vereint ist, hat sich erst in neuerer Zeit verallgemeinert und auch hier liegt wieder die Schwierigkeit darin, daß die Träger einer Spina bifida occulta wohl selten an ihren Folgen, sondern an anderen Krankheiten zugrunde gehen und letztere dann bei der etwaigen Obduktion im Vordergrund stehen. So konmt es, da $\beta$ die meisten der notierten Befunde in vivo bei Operationen gewonnen wurden. Solche aber sind vorsichtig zu bewerten, namentlich hinsichtlich der ihnen beigelegten Bedeutung. Hier mag of t der Wunsch der Vater des Gedankens sein! Ich will jedoch nicht die Objektivitit in der Berichterstattung in Zweifel setzen, sondern möchte nur zur Sliepsis mahnen gegenüber den aus den Befunden hergeleiteten Folgerungen, denen ich gewisse Bedenken entgegensetzen werde.

Betrachten wir zunichst die Veränderungen im Gebiet des Kreuzbeines und der Lendenwirbelsitule und gehen wir von außen mach innen vor, so kann in vielen Fiillen an der Haut jegliches Merkmal einer Defektbildung fohlen. Die von vielen als pathognomisch angegebene Hypertrichosis konnte in den hier beobachteten Fällen nicht ein einziges Mal festgestellt werden. Das ,.unschuldige" Grübchen (Dun cker) einer mehr oder weniger gut ausgebildeten Fovea coccygea trat dagegen mehrfach in Erscheinung. Schmerzpunkte fehlten vollkommen. Knochendeformitäten ließen sich nicht mit Sicherheit palpieren; wohl fand sich in einigen Fällen eine auffallende Weite des Hiatus sacralis oder blieben die Processi spinosi von Lumbalis V und IV unter dem Niveau der angrenzenden zurück, Vergleiche mit Gesunden aber lehrten, daß diese Zeichen nicht eindeutig sind. Die Knochenveränderungen zeigten sich auf den Röntgenbildern in den vielfach beschriebenen Varietäten, deren genaue 
Aufzählung und Beschreibung erläßlich scheint, da der Knochendefekt, wie die Vergleichung der in der Literatur veröffentlichten Fälle (Fischer, von Recklinghausen, Ribbert. Brunner u. a.) ergibt, keineriei Anhaltspunkte für einen Rückschluß auf Art und Sitz der Markstörung gewährt. Es macht allerdings den Anschein, als ob bei lumbalem Sitz der Wirbeldehiszenz die Verbildungen an den Füßen hochgradiger sind als bei rein sakralem Knochendefekt (namentlich bei Duncker); doch lassen sich auch zahlreiche Fälle zusammenstellen, in denen sich hochgradigste Fußdeformitïten mit rein sakralen Defekten vereinen (Beck, Bibergeil).

Bedeutungsvoller als diese nur kurz erwähnten ,,äußeren “ Veränderungen sind die bei der Eröffnung des Lumbosak ralkanals sich darbietenden Abweichungen von der Norm und mit diesen vereint die auf Querschnitten des weichen Kanalinhaltes sich ergebenden pathologischen Verhältnisse. Ich muß mich hier in wesentlichen auf Berichte in der Literatur beschrïnken. Ein Fall von Spina bifida occulta mit beiderseitigem, schwerem Plattfu $B$ und Incontinentia urinae. der seit langem an ausgedehnter Darmtuberkulose leidet, soll post mortem weiter untersucht werden.

Wenn sich in der frühesten embryonalen Periode die Umbildung der Rückenfurche zum Rückgratsrohr nicht in glatter Weise vollzieht, indem sich Medullarplatte und Hornblatt nicht tremnen, so daß nun die Membrana reuniens posterior, aus der sich die knöchernen Bogen bilden, nicht hindurchwachsen kann, so haben wir wahrscheinlich die direktesten Folgen davon in den ron Duncker und anderen beschriebenen Narbensträngen vor uns, die von der Haut (mitunter der Fovea coccygea) ausgehend durch den Wirbelspalt hindurchtreten und mit dem Kanalinhalt verwachsen oder verklebt sind. Es ist die Lamina epithelio serosa, die von den Rückenmarkshäuten (Arachnoiclea) ausgehend bis zur Unterfläche der Haut führt (Denucé). Frreicht sic anch nicht immer in dieser ausgesprochenen narbigen Strangform die Körperhaut oder wenigstens die aus der ehemaligen Membrana reuniens sich bildenden fibrösen und zum Teil unregelmäßig verknöcherten Verschlußstellen der Knochenspalten in den Wirbelbögen, so wird sie doch in vielen Fällen Fixierung des beweglicheren Kanalinhaltes mit der starren Wandung bedingen können. Es hat nun etwas Verlockendes an sich, diese dem Mark angelegte Fessel, die es an dem normalen Emporsteigen im Wirbelkanal hindern soll, als Ursache für die erst im Laufe der Jahre auftretenden, langsam progredienten FuBcleformitiaten anzusehen. Und es tindet sich auch zuweilen ein augenfälliger Beweis für cliese Arretierung: die ans dem abwärts gezogenen Conus medullaris austretenden Nervenwurzeln senken sich nicht wie sonst in einem spitzen Winkel zu ihrem Durchtrittsforamen kaudalwärts, sondern steigen direkt rïckläufig zu dem entsprechenden Foramen empor. In dieser Art wird ein sehr interessunter Fall bei Fischer-von Recklinghausen beschrieben. Bei dem 25jährigen Mann mit Hypertrichosis in der Kreuzbeingegend und linksseitigem Klumpfuß stand der Conus merdullaris in der Höhe des zweiten Kreuzbeinwirbels und nicht, wie es hätto sein müssen. in der Höhe des oberen Randes des zweiten Iumbalwirbels (Spalteholz u. a.). Der physiologische Vorgang des Emporsteigens der Medulla ist also unterblieben. Kann nun diese "Fesselung des Marks", die doch in denkbarer Weise durch ihre Zerrung chronische Reizzustände. 
Druckstellen und andere krankhafte Vorgänge an Jark und austretenden Nerven hervorrufen könnte, eine befriedigende Erklärung abgeben für dic in Rede stehenden progredienten Fußdeformitaten? Cind vor allem: deckt sich das klinische Bild wenigstens in einem nennenswerten Prozentsatz mit den Erscheinungen, die ein derartiger mechanischer Insult des unteren Rückenmarks nach sich ziehen würde? Und endlich, wemn nicht, wie ist dann diese lesselung des Marks zu bewerten?

Zunächst findet sich in der erwähnten Arbeit selbst eine Angabe, die das Tieferstehen des Konus in ganz anderer Weise erklärt. Ich führe sie an, weil nach ihr von vorneherein die Annahme einer Fesselung und Arretierung des Marks illusorisch wäre, kann jedoch njcht lange über ihr Für und Widler streiten, da mir weitere Literatur darüber nicht zur Verfügung stand. Es wird clort nämlich gesagt: Wir haben es mit einem Nißverhältnis im Wachstum zwischen Mark und Wirbelkanal zu tun - aber das Rückenmark wächst zu lang!. (ler Wirbelkanal (als Vitium primae formationis aufgefaßt) wächst zu kurz! -

Kehren wir jedoch zu dem Moment der Arretierung zurïck. Auch hier ergeben sich ungelöste Schwierigkeiten, die dem Vorgang der Fesselung in rlieser grobmechanischen Auffassung mur für seltene Fälle eine berechtigte Bedeutung lassen. Nach Ranke steht der Conus medullaris schon im fünten bis sechsten Monat des uterinen Lebens in der Höhe des III. Lumbalwirbels, er steigt also von da ab nur noch um einen Wirbel in die Höhe. Um dieses letzte, kurze Maß zurückzulegen resp. zurückzubleiben, ist eine Spanne Zeit von mehr als zehn Jahren erforderlich - und in diesen Jahren ist der Wachstumsunterschied schon sehr minimal und nimmt immer mehr ab. Wie sollen da etwa die Zerrungen gerade erst im siebten oder gar nach dem fünfzehnten Lebensjahr so besonders hochgradig werden, daß sie durch Störung in den nervösen Elementen zu einer Fußverkrümmung führen, während sie in den vorhergehenden Jahren, da doch die Wachstumsinkongruenz eine erheblich stärkere war, ohne jeden EinfluB geblieben sind? - Zweitens sind die Fußs. deformitäten in weitaus der Mehrzahl der Fälle einseitig: und drittens fehlen sensible Störungen oft ganz oder stehen in gar keinen Verhältnis zu den hochgradigen Störungen in den motorischen Daten. Wie soll das mit einer Arretierung des gesamton Marks erklärt werden? Da -- wie oben gezeigt wurde - die sensible Komponente a priori weniger gestört ist als die motorische, so müßte sich gerade in dieser sensiblen sphäre die Schädigung am ehesten und deutlichsten verraten. Zwei Klaviere: das eine intakt, das andere mit vielen gesprungenen saiten, beide erleiden durch Feuchtigkeit eine Quellung des Rahmens. An welchem wird sich die dadurch hervorgerufene Zerrung der Saiten am vielseitigsten und eklatantesten nachweisen lassen? Kein Zweifel! - Zudem möchte ich noch auf die oft recht derben Bindegewebszüge anfmerksam machen, die namentlich im untersten Teil von der Facies anterior der spinalen Dura mater zu dem Ligamentum longitudinale posterius ziehen und diese hiermit rerlöten. Man hat sie nie beschuldigt, das Mark am Aufsteigen gehindert zu haben. Mag sein, daß diese eben der Norm entsprechend mitwachsen, während der alypische Strang an der Hinterseite im Wachstum nicht Schritt halten kann, - so fehlen aber doch noch immer an den austretenden Nervenwurzeln und den Spinalganglien, die in ihrem jeweiligen Foramen intervertebrale gleichsam ver- 
ankert liegen, Befunde, wie sie für derartige mechanische Insulte (Zug, Knickung, Druck) verlangt werden müssen. Oder man müßte annehmen, daß diese Anderung so langsam vor sich gehe, daß der Nerv Zeit hat, sich anzupassen: danit fiele jedoch zugleich auch die Annahme einer Schädigung des Pückenmarks resp. seiner Verlängerung durch eine Arretierung, die ein bisher normal funktionierendes Wark in dieser seiner Funktion erheblich verändert. so daß eine pathologische fiußstellung daraus resultiert. Wenn man nun aber doch mal in eine fortschreitende Schädigung des Marks und der von ihm ausgehenden Nerven durch die „Fesselung" festhalten will, dann mïssen zur Sicherung der Diagnose folgende Postulate erfïllt sein: 1. Beginn der progredienten Störung sehon in frühesten Kindesalter. 2. Störtingen an beiden unteren Extremitïten. wemn auch in ungleichem Grade. 3. Zunehmende Störungen im motorischen, aber auch ebenso im sensiblen Gebiet (ïber das ref raktïre Verhalten des letzteren gegenüber mechanischen Schädigungen siehe weiter unten). Sind diese drei Punk te positiv und klar, dann kann man mit großer Wahrscheinlichkeit (nicht Sicherhejt) auf eine solche mechanische Behinderung des Aufsteigens der Meclulla schließen und daraus die zutage liegenden Sóchädigungen erklären. Gleichzeitig wäre der Weg der Therapie: operative Beseitigung der Fessel gegeben. Nun ist aber, wie schon betont wurde, das Krankheitsbild in den wenigsten Fällen in dieser Weise vollkommen, und je mehr Lücken in jenem dreigliedrigen Symptomenkomplex vorhanden sind, un so zweifelhafter und unwahrscheinlicher wird die sich darauf gründende Diagnose der Fesselung in cler Art, wie sie von manchen Autoren als grob-mechanisch schädigendes Moment beschuldigt wird. Nun hat aber die operative Entfernung von narbigen Strängen und Verwachsungen, auch in Fïllen, in denen das Krankheitsbild obige Symptomtrias vollkommen vermissen ließ. dennoch zu ausgezeichneten Erfolgen geführt (Literatur und eigene Beobachtung). Dies ist nur zu erklären. wenn man neben der - ich wiederhole es abermals - grob-mechanischen Schädigung durch die Fessel eine mehr feinere Einwirkung einer solchen pathologischen Fixierung auf das ,in der Entwicklung gehemmte Mark" annimmt. Wie ich mir diese denke und wie sie sich in schönster Weise mit dem Symptomenbild unserer Krankheit in Einklang bringen läßt, wird später zu sagen sein.

Bei der \%weiten Art pathologischer Veränderungen, die sich nach Eröffnung des Markkanals dem Untersuchenden darbieten und als langsam fortschreitende schädligung des Marks imponieren können, sind ganz ähnliche Gesichtspunkte wie oben geltend zu machen. Es handelt sich um Geschwulstbildungen, die zwischen Mark und Kanalwandung liegend das erstere einengen und einem wachsenden Druck aussetzen. So lehrt es der Augenschein. Man sieht den oft. erweiterten Kanalraum ${ }^{1}$ ) ron einer Fettgeschwulst eingenommen; diese schmiegt

1) Die von einer Spaltbildung betroffenen Wirbel sind of im ganzen breiter als normal. Bei einem Spalt im Bogen ron Lumbalis $V$ glich die Lendenwirbelsäule einer Pyramide, deren auffallend breite Basis der Körper des fünften Lendenwirbels bildete, während dann kontinuierlich die Breite bis zum untersten Brustwirbel rasch abnahm. Ubrigens ein Zeichen, daß auch Lumbal IV und III noch unter der gleichen Schädigung zu leiden hatten wie $V$, wenn es auch zu einer Spaltbildung nicbt gekommen war, und daß sicher in dieser Höhe noch primäre Defekte im Mark festzustellen sind. Bei dem Patienten - 8jähriger "Junge - fand sich nur leichter beginnender Pes equino-vams excavatus links. 
sich der Form des Marks, das infolge der primären Dysplasie eine unregelmä Bige Oberfläche hat, bald dïnner, bald dicker ist, genall an und scheint das Mark an den verjüngten Stellen komprimiert zu haben. Dieses ", Quasi ex vacuo" (Duncker) angelegte Fettgewebe füllt den sonst leeren Raum zwischen dem Vark und der Kanalwandung aus (wie überhaupt der Organismus das Bestreben hat, eine unphysiologische Leere mit Gewebe - Fett - auszufüllen, Bier) und ist nicht etwa von vornherein als eine Geschwulst aufzufassen, die das Wark verdrïngt und zusammengepreßt haben könnte. Es ist nichts anderes als das Fettpolster, das sich auch normalerweise neben Bindegewebe und Venengeflecht in dem Raum zwischen Dura spinalis und Periost vorfindet. Selbstverständlich können an dieser Stelle auch Tumoren vorkommen. Das ursprünglich als normales, umhüllendes Fettpolster angelegte Gewebe entwickelt aus irgendoinem Anlaß ein selbständiges Wachstum, wie es den Geschwiilsten eignet oder aber der Tumor wird schon als solcher kongenital mit zur Welt gebracht. In letzter Form gehört er zu den Klassen der kongenitalen Geschwülste in der Kreuzbeingegend, von denen von Bergmann drei unterscheidet: Kavernöse und zystoide Lymphangiome, Teratome und endlich Fettgeschwülste. Von diesen Tumoren ist aber in der gleichen Arbeit schon zu lesen, daB sie viel häufiger ohne eine Beziehung zum Rückenmark und seinen Häuten zu finden sind, als daß sie mit jenen in irgendeiner Beziehung stehen. Beachtet man nun, daß die meisten dieser Fettgeschwïlste schon in der frühesten Kindheit sich als solche manifestierten und nicht erst in spïterem Leben durch plötzliches Wachstum und Größerwerden imponierten, so bleibt für die Annahme eines intrakanalären Fettumors, der erst etwa im 6. oder gar 16. Lebensjahr zu wachsen und das Pückenmark in seiner Art als selbständig wachsender Tumor zu komprimieren anfing. recht wenig Wahrscheinlichkeit.

Die anzutreffenden Geschwülste sind nun nicht immer rein lipomatöser Art, sondern häufiger von der Art der Mischgeschwülste und bieten sich dar als Myofibrolipome. Die Anordnung der mitunter recht zahlreich ausgebildeten Muskelelemente (Ribbert), die der Lage und Verlaufsrichtung der tiefen Rüickenmuskulatur (Musculus multifidus) entsprechen, läßt einen Rüickschluß iuf Zeit und Art der Entstehung dieser ,Tumoren" zu: Nach Fischer-von Puecklinghausen liegt die Störung der Keimanlage in jener Zeit, da die Muskelkeime sich von den Anlagen der Wirbelkörper sonderten. Solche abgesprengten Keime können nun allerdings leicht zu einen selbständigen Wachstum kommen, spielen sie doch in der Geschwulstlehre eine große Rolle; aber dann müßten sie auch ein atypisches Wachstum zeigen, wie es sich in Fibromen und Myomen findet. Derartige Feststellungen sind mir in der Literatur der Spina bifida occulta nicht begegnet; ja, die oben zitierten Befunde von typischer Anordnung der Muskelfasern widersprechen sogar der Annahme eines selbständig wachsenden Tumors. Wir haben in vielen Fällen nur eine Verlagerung von normal differenzierten Geweben an einen unphysiologischen Ort. Dieses deplazierte Gewebe kann natürlich auf die Umgebung unter Umständen einen anderen Einfluß ausüben, zumal, wenn es ein so empfindliches Organ wie das Nervensystem ist und letzteres auch noch selbst unter pathologischen Veränderungen zu leiden hat. Ich erinnere nur an überzählige Halsrippen, die in ihrer unphysiologischen Lage die umgebenden Gewebe sehr stark irritieren können, ohne 
darum zu den Geschwülsten mit selbständigem Wachstum zu gehōren. Auf der anderen Seite aber ist richtige Geschwulstbildung möglich, wenn auch vielleicht selten. Schon der Cimstand, daß bisher anscheinend nie beobachtet worden ist, daß das Krankheitsbild der Spina bifida occulta mit progredienter Fußverkrïppelung im späteren Alter zu einer kompletten Lähmung der vom untersten Mark versorgten Körperakschnitte geführt hätte, muß die Diagnose auf 'Tumor in Zweifel setzen. Es mïßte denn sein, daß der Tumor nur im Laufe einer beschränkten Anzahl von Jahren ein selbständiges Wachstum zeigte, um später dieses atypische Verhalten wieder einzustellen, oder aber der Tumor so eminent langsam wachsen, daß es nicht mehr zu solchen Ausfallserscheinungen kommt.

Nehmen wir aber einen Tumor als schädigendes Agens an, dann müssen wir wieder eine Reihe von Postulaten aufstellen, deren Erfüllung zur Sicherung der Diagnose notwendig ist. $\mathrm{Da}$ die progrediente Fußdeformität, wenn sie in Behandlung kommt, meist wohl schon Jahre hindurch besteht. so müssen, zumal der Tumor seiner Genese nach an der Hinterseite sitzt, auch zunehmende, deutliche Sensibilitätsstörungen oder sogenannte Wurzelsymptome sich nachweisen lassen, und in länger bestehenden Fällen müssen auch Störungen auf beiden Seiten vorhanden sein, wenn auch hier der Linterschied größer sein kann als wie bei einer Fesselung des Marks. Tumoren, die von außen das Riickenmark angreifen, machen eher doppeltseitige Erscheinungen als solche, die in der Substanz des Marks selbst ihren Sitz haben.

Bei spondylitischen Iähmungen scheinen sensible Störungen ebenfalls meist ganz zu fehlen. Dies könnte zur Entkräftung meiner oben aufgestellten Postulate angeführt werden. Dazu wäre zu bemerken: 1. Bei der spondylitischen Lähmung findet sich in fast allen Fällen zum wenigsten eine Hyperästhesie aller Empfindungsqualitäten (Renz bei Hoffa). 2. Bei der spondylitischen Lähmung kommt der Druck zumeist von der Vorderseite sowohl bei Abszeßbildung wie bei Zusanmenbruch eines Wirbelkörpers, während bei Spina bifida occulta Fessel und Geschwulst an der Hinterseite sitzen. 3. Findlich sind (nach Strümpell) die sensiblen Fasern gegen Druck unempfindlicher als die motorischen, sie werden also bei der verhältnismäßig rasch vorwärtsschreitenden Schädigung bei Spondylitis gar nicht mebr Zeit finden, in Erscheinung zu treten, da entweder Heilung, spontaner Stillstand oder Exitus eintritt. Immerhin mag man dem Umstande, daß die sensiblen Bahnen widerstandsfähiger sind und (nach Moritz bei von Mering) infolge ihrer geschützteren Lage im Innern des Marks schädigendem Druck von außen weniger ausgesetzt sind, Rechnung tragen, so scheint es mir doch billig, zu verlangen, daß bei jahrelangem Einwirken der mechanischen Schädigung - Druck oder Zerrung und bei dem Sitz dieser Sehädigung vornehmlich an der Hinterseite sich auch progrediente Störungen in der Gefühlssphäre nachweisen lassen.

Fesselung durch Strangbildung und dadurch bedingte Abschnürung, Zerrung und Abluickung von austretenden Nervenwurzeln einerseits und Verengerung des Raumes zwischen Mark und knöcherner Kanalwandung und dadurch bedingte Verlagerung. Kompression und vollständige Abquetschung von Markteilen andererseits sind Veränderungen, die wirklich unter Umständen progrediente Anomalien an den unteren Extremitüten verursachen kōnnen - analog anderen fortschreitenden Erkrankungen des Zentralnervensystems. 
Ich erwähnte schon Fälle. in denen der Erfolg des therapeutischen Eingriffes die Annahme einer Schädigung der nervösen Substanz in der geschilderten Art durch Fessel oder Tumor zu beweisen scheint. Ich füge noch zwei Beispiele an, die in ihrer Deutung jedoch nicht mehr so klar sind und uns überleiten zu der großen Masse von Fällen besagter Krankheit. bei denen klinisch Fesselung und Tumordruck sich nicht einwandfrei nachweisen lassen. bei denen in vivo vorgenommene Autopsie keine pathologischen Verïnderungen erkennen lïßt oder die trotz schönster operativer Entfernung einer Arretierung oder einer tumorähnlichen Wucherung unverïndert progredient bleiben. Sie führen uns nämlich zu deu Verhältnissen am Marksystem selbst.

Zunächst scheint die Methode von Cathelin dem mechanischen Moment der Behinderung des physiologischen Aufsteigens der Medulta durch eine Fesse] das Wort zu sprechen. Cathelin behandelte die Kinuretiker mit seinen epiduralen Injektionen und will dabei 20 bis $25 \%$ Heilungen gesehen haben. Durch Injektion größerer Mengen seiner Lösung (physiologische Kochsalzlösung $+0,5 \%$ Novokain) können nämlich Verwachsungen sehr wohl mechanisch gedehnt werden. Dies wird als Argument für mechanische Dehnung einer Arretierung angefiihrt, scheint mir aber wenig beweisend, da absolut nicht eindeutig. Zunächst einmal ist nicht festgestellt, ob bei all den Enuretikern eine Spina bifida occulta als ätiologisches Moment in Frage kam. Nach Angabe mancher Autoren soll sich allerdings bei über der Hälfte von pathologischen Bettnässern eine Spinia bifida occulta finden. Nun läßt sich aber mit statistischen Zahlen herrlich leicht jonglieren! So war unter den hier beobachteten Fïllen von ausgesprochener spina bifida occulta nur ein Bettnässer; das wären von diesen nicht ganz 2,5\%. Diese Zahlen sagen uns, daß auf die halbe Zahl der Bettnässer die vierzigfache Anzahl von Leuten mit Spini bifida occulta käme. Wären zum Beispiel in genischtem Material 10 Bettnässer, so wären ron diesen 5 mit einer Wirbelspalte behaftet, auf je einen dieser fünf kïmen aber wiederum 40 Personen mit Spina bifida occulta, das machte für die zehn Bettnässer 200 Fälle von Spina bitida occulta! So häufig ist die Spina bifida occulta im Verhältnis zur Enuresis nocturna wahrhaftig nicht. Doch Verzeihung, ich wollte nur dartun. daß Statistiken immerhin mit größter Vorsicht zu bewerten sind. Es spielen bei der Enuresis nocturna so viel verschiedene Faktoren eine Rolle. daß man meines Erachtens die Wirbelspalte nicht ir jedem zweiten Falle als Ursache ansprechen durf. Damit fällt aber die Bedeutung der bei Cathelin angeführten Zahlen. Ferner ist wohl allgemein bekannt. d:a die Enuresis nocturna in ganz eminenter Weise einer Psychotherapic zngängig ist und sich sehr oft mit zunehmendem Alter von selbst verliert, also keine Progredienz aufweist gleich den anderen Erscheinungen bei der Spina. bifida occulta. Zu der nicht zu leugnenden Beeinflussung der Psyche, speziell der kindlichen, durch mehrfach wiederholte Sakralinjektionen treten noch direkte Einwirkungen der Lösungen auf das Mark selbst, die den günstigen Effekt hervorrufen können. (Das Novokain mag die rein automatische Erregbarkejt des Reflexzentrums für die Blasenentleerung herabsetzen, so daß nur die willkürliche Regelung nachdrücklicher sich auswirken kann.)

Als Kuriosum sei hier noch die Methode von Heubner erwähnt, der die kleinen Bettnüsser an den Beinen aufhing und sie so von ihrem Leiden 
befreite. Auch hier kann man das mechanische Moment der Dehnung als Therapeutikum anschen; doch glaube ich, daß diese liebevolle Behandlung auch Findruck auf das kindliche Gemuit macht! Welchem ron beiden der erste Rang einzuräumen ist, will ich hier unentschieden lassen.

Durch operative Entfernung von Tumoren und Verwachsungen sind Besserungen, ja selbst Heilungen erzielt worden. Das ist wohl eine unbestreitbare Tatsache, man müßte sonst die Berichte namhafter Autoren für falsch und irrig erklären. Ist nun die Einwirkung der beiden Schädigungen Druck und Fessel auf das Mark immer so aufzufassen wie etwa bei der spondylitischen Iähmungr. die vielfach durch Abquetschung infolge Zusammensinkens der Wirbel oder durch Druck eines thszesses (entzündliches Ödem der Umgebung unberücksichtigt) verursacht wird und nach Beseitigung der Riickenmarksinkommodation ein Schwinden der Lühmungserscheinungen zeigt? Wie wären dann diejenigen Fälle progredienter Art zu deuten, die bei der Operation weder einen Tumor noch eine Fessel aufwiesen (eigene Beobachtung) und die Fälle, die trotz der Operation fortschreitend blieben? Ganz abgesehen davon. daß in vielen Fällen das klinische Bild sich nicht mit dem Bilde eines Rüickenmarkstumors decht. In den Fällen der Arretierung, die, wie gezeigt wurde. zur Hauptsache im uterinen Dasein effektiv ist, wäre die Prognose eines Eingriffes weniger günstig. Monate, ja bis Jahresfrist dauernde spondylitische Lähmungen sind geheilt worden, ob aber auch ein Mark, das durch fünf bis zehn .Jahre hindurch bestehende Einwirkung in seinem Bau geschädigt wurde, noch der Reparatur fähig ist, scheint mir mehr als zweifelhaft. Und gerade mit so langdauernden Veränderungen haben wir es vielfach bei dem Bilde der Spina bifida zu tun. Wenn nun trotzdem des öteren auffallende Besserungen nach der Entfernung einer solchen Fessel, die seit Jahren auf das Rückenmark wirkte, konstatiert werden konnte, so dïrfen wir uns die durch besagte Fessel hervorgerufene Veränderung im Mark nicht in dem Sinn einer manifesten. irreparablen, anatomisch-histologisch nachweisbaren Umbildung in der nervösen Substanz vorstellen, sondern müssen mehr an eine Reizwirkung auf das schon mit Defekten behaftete Mark denken. Das gleiche gilt für die Einwirkung des ,Fettumors: . Solche böten natürlich für einen operativen Eingriff ein ̈̈ußerst günstiges Feld. Wie wir uns eine derartige Reizwirkung vorzustellen haben, soll weiter unten erörtert werden, nachdem wir noch andere Fakta besprochen haben. die ebenfalls für die Progredienz der Krankheit beschuldigt worden sind. Es bleibt nämlich noch zweierlei zur Erklïrung dieser Erscheinung: Fortschreitende Veränderungen im Mark resp. in den Nervengebilden oder progressive Veränderungen an Muskel und Knochen, während die Fehlbildungen im Mark stationär bleiben.

Wic ist es mit der erst genannten Möglichkeit, haben wir es bei der verborgenen Wirbelspalte mit fortschreitender Fußverbildung mit einem chronischprogressiven Krankheitsprozeß im Rückenmark zu tun? Henne berg berichtete in einer sitzung der Berliner Gesellschaft für Psychiatrie und Nervenkrankheiten ̈̈ber Rüickenmarksbefunde bei Spina bifida und sagt im Selbstreferat: „In den geschlossenen Rückenmarksteilen findet sich Hydromyelie und Spaltbildungen, die denen bei Syringomyelie völlig gleichen. Es kommt zu Nekrosen und Spalten in der grauen Substanz, Begrenzung des Spaltes durch 
Bindegewebe, Stehenbleiben von Gewebsbalken in den Spalten. Der Prozeß ist ein langsam progressiver. Manche Fälle von Syringomyelie und Hydro. myelie können als rudimentäre Spina bifida aufgefaßt werden." Henneberg machte diese Feststellungen bei drei Kindern, von denen das älteste $3^{1 / 2}$ Monate alt war und die an Rachischisis partialis oder Myelomeningozele litten: doch darf man wohl von diesen Befunden Rückschlïsse auf die Verïnderungen bei einem geringeren Grad der gleichen Mißbildung machen - bei der Spina bitida occulta. Unklar ist mir, wieso Henneberg die langsane Progredienz der Erkrankung aus den beschriebenen Fällen herleiten konnte. Das Lebensalter der Kinder ist entschieden zu kurz, um Anhaltspunkte für eine Progredienz zu geben, and die Folgerung, daß das Leiden fortschreitend wïre, weil sich bei ihm Rückenmarksverïnderungen zeigten gleich denen bei der progressiven Syringomyelie, ist wohl kaum zu rechtfertigen. Allerdings finden sich auch andere Verwandtschaftszeichen der beiden Krankheiten. Haben wir hier die Ahnlichkeit in bezug auf den Rückenmarksbefund, so begegneten andere Autoren den gleïchen Fußmißbildungen bei beiden Leiden. Duncker zeigt in seiner Arbeit das Bild eines schönen Spitzhohlfußes, der weder seinem Adspekt, noch seiner progredienten Entwicklung nach sich von anderen Spitzhohlfüßen bei Spina bifida occultia wesentlich unterschied. Und drittens endlich sagen uns die Neurologen, daß3 die Entstehung der Syringomyelie in der Mehrzahl der Fälle durch eine fehlerhafte kongenitale Anlage bewrkt wird (Moritz), wit: wir es auch bei der Spina bifida und ihren verschiedenen Abstufungen haben. So ist allerdings der Schluß: das Wesen der krankhaften Veränderungen am Mark bei der Wirbeldehiszenz ist dasselbe wie bei der Syringomyelie und bedingt somit den progressiren Charakter der FulBdeformitäten in der gleichen Art wie die Syringomyelie - sehr naheliegend. Wenn wirklich eine angeborene Jefektbildung der Ausgangspunkt für die Syringomyelie sein sollte (was nicht bewiesen ist), so muß doch noch ein zweites hinzukommen, das die weiter fortschreitende Höhen bildung verursacht. (Es mag sein, daß ein in der Entwicklung geschädigtes Mark für diese ,Noxe* empfänglicher ist.) Ein Analogon einer s päter sich ausdehnenden und bisher gesundes Gevebe vernichtenden kongenitalen Mißbildung, die sich dann als höherer Grad dieser Mißbildung darstellen würde, gibt es meines Wissens nicht. Dazu kommt, daß der Lieblingssitz der Syringonyelie das Halsmark ist und daß die drei Hauptsymptome der Syringomyelie: degenerative Muskelatrophie, dissoziierte Empfindungsläkmungen und trophische Störungen namentlich an Haut und Nägeln sich in den meisten Fällen von Spina bifida occulta nicht in der einwandfreien Klarheit nachweisen lassen, wie es zur Diagnose der Syringonyelie erforderlich wäre. Ferner ist mir in der Literatur kein Fall von Spina bifida begegnet, bei dem die an den Füßen beginnenden krankhaften Erscheinungen im späteren Leben auch auf die oberen Extremitäten übergegriffen hätten. Brunner erwähnt einen vielleicht an eine, aufsteigende" Syringomyelie erinnernden Fall von Spina bifida bei einem 20jährigen Mann, der den an antiken Statuen manchen Beschauer ergötzenden Haarschopf trug. Die Füße des Patienten sollen ursprïnglich normal gewesen sein. Im Alter von 7 Jahren zog sich der Junge eine s ch merzf reie Verletzung der rechten Fußsohle zu. Diese Wunde trotzte jeder Behandlung. und im Laufe der .Tahre trat der FuB in alssgexprochene KlumptuBstellung. 
Hier könnte man an eine beginnende lumbale Syringomyelie denken; wir haben motorische, sensible und trophische Störungen in deutlichster Weise. Und doch war es keine Syringomyelie. Ribbert berichtet an anderer Stelle über die Sektion dieses Falles: Der Konus stand in normaler Höhe. Die Kauda war clïnner und weniger nervenreich als sonst. Strangförmiges Mvofibrolipom mit zahlreichen Muskelelementen. Riickenmarksquerschnitte in vorderen Partien fast normal, ausgesprochene Störungen in der hinteren Hälfte. Intervertebralganglien normal. Also eine kongenitale Rückenmarksmißbildung, deren Zentrum im posterioren Teile sitzt und die dementsprechend in erster Linie eine Störung in der Gefühlssphäre mit sich brachte. Wiederholen möchte ich auch hjer, daß weder das strangförmige Myofibrolipom eine Fesselung hewirken konnte, noch daß etwas von einer Kompression des Markes durch die Mischgeschwulst erwähnt wird. Trotzdem haben wir das Bild einer anscheinend progredienten Erkrankung des Rückenmarks vor uns. Anscheinend, denn die Defektbildung inı Rückenmark war stationär, dagegen vermochte der Organismus infolge der erheblichen Störung der rezipierenden Regelung der motorischen, sensiblen und, wenn man will, nutritiven Vorgänge auf die Dauer den schädigenden Finflüssen, den die Funktion des Beines mit sich brachte, nicht zu widerstehen und zeitigte so das Bild einer progredienten Erhrankung. Leider fehlen bisher genauere Untersuchungen, die mit besonderer Berücksichtigung dieser Faktoren in Rïckenmarksschnitten vorgenommen wären. Es mag dies, wie schon eingangs gesagt wurde, darin begründet sein, daß nur sehr selten ein Fall ron Spina bifida occulta mit progredienter Fußdeformität in solcher Weise zur Untersuchung der Pathologen kommt. Wir müssen daher aus dem klinischen Bild einen Rïckschlu 1 auf Art und Sitz der krankhaften Veränderungen (namentlich in bezug auf genaueste Lokalisation) im Mark machen. Es fehlt diesen Schlußfolgerungen dann allerdings zum Teil das pathologisch-anatomische Substrat.

In diesen primären und stationären Veränderungen im Mark haben wir ein erstes und wichtigstes Moment für die Entstehung einer fortschreitenden Fußdeformität zu erkennen. Sie treten erst dann in Erscheinung, wenn sie durch die Funktion wirksam werden. Um dies klarer zu umgrenzen, müssen wir auf die normale Physiologie des Zentralnervensystems zurückgreifen.

Der motorische Willensimpuls gelangt von den kortikalen Zentren der Großhirnrinde, wo er bewußt entsteht, zumeist anf dem Wege des Tractus corticospinalis lateralis und anterior zu den motorischen Ganglienzellen der Vorderhörner, nachdem sich diese Bahnen zuvor gekreuzt haben. Von hier geht der Reiz durch die vordere Wurzel in den Nervus spinalis. dessen weitere Verzweigungen die peripheren Nerven bilden. Der größte Prozentsatz der Fasern der Pyramidenbahnen steigen in der Norm in dem Seitenstrang abwärts und nur 8 bis $20 \%$ bilden den Vorderstrang. Zu beachten ist, daß die Pyramidenseitenstrangbahn sich infolge der Abgabe der Fasern an die Vorderhörner an der unteren Grenze der Lendenanschwellung, in deren Höhe sie schon sehr verjüngt ist, gänzlich erschöpft und die Vorderstrangbahnen im mittleren Brustmark schon ihr Ende finden, so daß wir also unterhalb der Intumescentia lumbalis keine Pyramidenbahn mehr antreffen. Diese Lendenanschwellung 
reicht bis zum 1. Lendenwirbel (mitunter auch etwas tiefer) and geht dort in den Conus medullaris über. Das Ende der motorischen Großhirnmarkbahnen liegt somit um ein Bedeutendes höher als die Knochendefekte bei der in Frage stehenden Spina bifida veculta. die sich meist am oberen Kreuzbein und an den beiden untersten Lendenwirbeln finden. Doch dïrfen wir diesem Umstande nicht allzu große Bedeutung beilegen; dem zur Zeit der Entstehung der Mibbildung liegen die betreffenden Markelemente noch in der gleichen Höhe mit dem späteren Kreuzbein resp. Lendenwirbel. Es rückt also erst im Laufe der . Jahre, falls nicht eine Arretierung die alten Bedingungen fixiert, der Ort der Mißbildung im Mark vom Orte der Mißbildung am Skelett zentralwärts empor.

Eine allgemein bekannte 'Tatsache ist nun die, dals der Muskel, auch wenn der psychomotorische Impuls fehlt, nicht völlig erschlatft ist. Selbst im Schlaf ist die Muskulatur nie so gänzlich entspannt wie bei der Leiche (Bing). Diese Erscheinung nennt man Tonus der Muskulatur. Eine weitere, allgemein bekannte Tatsache ist, daß durch mechanische Reize, die auf bestimmte Stellen des Körpers (Sehnen, Hautbezirke, Knochen) einwirken, Kontraktionen von einem oder mehreren Muskeln ausgelöst werden. Diese Bewegungen sind in hohem Grade vom Willen unabhängig; es sind die Reflexbewegungen. sind nun Reflex und Tonus ihrem Wesen nach verschiedene Erscheinungen oder nur verschiedene Grade ein und derselben? In älteren Schriften begegnet man der Auffassung, daß dem Rückenmark selbständiy wirkende Zentren zukämen, die besagten Spannungszustand der Muskeln regelten und erhielten. Die Erscheinung des Reflexes wäre demnach mehr eine Sache für sich. Andere Forscher haben aber gezeigt. daß die Intaktheit der sensiblen Komponente für das Zustandekommen des Tonus unerlïßlich ist, da $B$ also mit anderen Worten durch stiandig zentripetal zufließende Reize (Berihrung, Lagegetühl, Druck, Schwere, Temperatur usw.) dieser Tonus ausgelost wird. Jamin kounte experimentell feststellen, ,daß schon eine partielle Ausschaltung solcher zentripetaler nervöser Einflïsse" (infolge des Fehlens der auf den Reflexbahnen den spinalen Zentren zuströmenden Erregungen und der dadurch herabgesetzten Funktion der motoriscken Bahnen), ,sich durch eine Steigerung des Muskelschwundes bemerkbar macht". (Wir haben hier gleich die doppelte Bedeutung dieses Reflexvorganges, der einerseits den Muskeltonus zu erhalten hat und andererseits aber auch der Erhaltung des Muskels dient.) Der Reflex ist nun meines Erachtens nichts weiteres als eine einen gewissen Grenzwert ïbersteigende, örtlich begrenzte Auswirkung solcher Reize. Es kann der von außen herantretende Reiz durch seine Höhe die Schwelle überschreiten und ein motorisches Phänomen auslösen oder aber ein unter der Schwelle bleibender Reiz auf ein empfänglicheres Marksystem treffen und in dieser Weise zur Erzeugung einer Reflexbewegung genügen. In diesem Falle hätten wir ein Nervensystem vor uns, dessen Toleranzgrenze (für geordnete rezipierende Regelung) tiefer liegt und somit leichter überschritten werden kann, als normalerweise sein sollte. Beim Tonus wie beim Reflex wird also stets ein von der Peripherie zentripetal gerichteter Reiz im Zentralnervensystem umgeschaltet und tritt zentrifugal als motorischer Reiz wieder in Erscheinung. Diese Transformierung findet im Rückenmark, und zwar ziemlich in derselben Höhe statt, in der Ein- und Austritt der betroffenen Nervenwurzeln liegen. Das verbindende 
Organ sind die Reflexkollateralen (Villiger u. a.). feine Nervenfasern, die aus der eintretenden hinteren Wurzel stammen (kurze Hinterwurzelfaser bing) und zu den motorischen Vorderhornzellen ziehen und sich wahrscheinlich erst an diesen aufsplittern, also direkt den äußeren Reiz übertragen. Doch ist der Weg nicht immer so einfach; es können ein und mehrere Neurone dazwischen liegen: Aufsplitterung an den Zellen der Hinterhörner oder erst Aufsteigen und dann t'bergreifen auf motorische Einheiten höherer Harkabschnitte oder selbst auf Umwegen Rückkehr zum gleichen Niveau (Bing). So erklärt sich auch die Möglichkeit der sogenannten .,L'mbahnung nervöser Impulse“ (Bickel), wenn sich etwa an der normalen Stelle der Umformung eines zentripetal einfließenden Reizes ein unüberwindbarer Widerstand entgegenstellt, so daß dieser gleichsam zurückgestant wird und nun sich mit erhöhter $\mathrm{K}_{\text {raft }}$ in seine "Nebenbahnen" ergießt und ein anderes als das gewohnte motorische Phänomen auslöst.

Das Canze: die zentripetalleitende Faser, das zur Hauptsache in der zellreichen Substanz gelegene System der Reflexzentren und die zentrifugalleitende Faser bilden zusammen den "Reflexbogen" (Rosemann). Aber hiermit ist der ganze Apparat des Reflexmechanismus noch nicht erschöpft. Es tritt nämlich eine sehr wichtige Kontrolle hinzu, die vor allem ein he m mendes Moment in sich birgt. Das sind die schon erwähnten kortikospinalen Fasern, die durch die Pyramidenbahnen an die Vorderhornzellen herankommen und sich dort auflösen. In diesen haben wir einen mächtigen Faktor, der den subkortikalen Innervationsmechanismus zügelt. Scheidet eine dieser zahlreichen. ïbereinander geschalteten Kontrollbahnen aus, so tritt eine Störung im normalen Spannungsgleichgewicht zwischen Stärke des einfließenden Reizes und der Größe seiner Auswirkung ein, und zwạr in dem Sinne, daß die der Kontrolle entzogenen Reflexbögen unter Cmständen eine bis ins Maßlose gesteigerte Empfindlichkeit zeigen. Für die Muskulatur bedeutet das Erhöhung des Tonus. $\mathrm{Ja}_{\mathrm{a}}$, es können Dauerspasmen auftreten, die schließlich zu endgültigen Kontrakturen führen. Beispiele dufür bringt in reichster Zahl die Klinik der Pyramidenerkrankungen.

Dies wäre einer der Fälle, di die Toleranzgrenze des Marksystems zirkumskript oder mehr allgemein erniedrigt ist und fast den Tullwert erreicht. In anderer Weise kann eine Herabsetzung der Toleranzgrenze dadurch hervorgerufen werden, daß in der nerrösen Substanz des Reflexbogens selbst (oder auch des ganzen nervösen Apparates - Bickel) eine erhöhte Reizbarkeit besteht, so daß schon ein geringwertiger Reiz die sonst blockierte Stelle durchpassiert. Hier entspricht die von oben kommende Hemmung der Xorm; aber der gleiche mechanische Insult, der sonst eine nur so schwache Reizwelle in dem Leitungssystem zu erzeugen vermag, daß sie sich an den entgegentretenden Hindernissen wirkungslos verliert, wirft in dem - fast möchte ich sagen beweglicheren, weniger trägen - sich durch erhöhte Reizbarkeit auszeichnenden Nervensystem gleich eine derartig heftige Welle auf, daß sie über alle Hemmungen hinwegeilt, auch in die ,Nebenbahnen" genügend starke Impulse hineinschickt. so $\operatorname{da} B$ die z. B. motorische Reaktion ausgedehntere Gebiete befällt als der Norm entspricht. Experimentell kann man solche im Reflexbogen selbst sich a bspielende Herabsetzung der Toleranzgrenze durch örtlich appliziertes Strychnin 
hervormfen. Auch sonst ist ja bekannt, daß örtliche Reizzustände im Rückenmark eine Steigerung der Reflexerscheinungen zur Folge haben.

Nicht fortschreitend. sondern stationär ist die Mißbildung im Mark bei der Spina bifidin occulta. Sie besteht aus herdförmigen Defekten, Spaltbildungen. Fermehrung des Stützgewebes. In höheren Graden sind die vorderen Bahnen und die Vorderhörner selbst und ebenso die hinteren Wurzeln und ihre Fortsetzungen namentlich in den Hinterhörnern mehr in Mitleidenschaft gezogen als bei den weniger schweren Erkrankungen, in denen vornehmlich der rezipierende Regulator getroffen ist. Dies erfordert das klinische Bild, das in den leichten Fällen zur Fauptsache spastisch-paretische Symptome aufweist. Sind die Markdefekte ausgedehnter, dann gesellen sich Sensibilitätsstörungen und motorische Ausfallserscheinungen in steigendem Maße hinzu. Dies erklärt sich auch zwanglos aus der Entstehungsart der Mißbildung, die eine Hemmung in der Schließung der Medullarplatte zum Medullarrohr darstellt - also an der Hinterseite ihren Sitz hat. dennoch aber die sensiblen, zentripetalen Bahuen wegen ihrer großen Unabhängigkeit von der Entwicklung des Medullarrohres weniger betritft. In Gegensatz zur poliomyelitischen Lähmung, bei der meist. geschlossene Einheiten der notorischen Vorderhornzentren ausfallen, sind hier die reinen Lähmungserscheinungen mehr disseminiert, nur einzelne Muskelbündel oder Muskelfasern treffend, so daß sie am Lebenden oft gar nicht nachzuweisen sind. Dies hat wiederun seinen Grund in dem Entstehungsmechanisnuus der Mißßbildung. Eine Hemmung im ZusammenschluB des Medullarrohres wirkt quer zur Achse des Ruickenmarkes, so dall zum Beispiel die im vierten Lumbalsegment heginnende und bis zum dritten Sakralsegment reichende Vorderhornzellsäule des Gastroknemius (Villiger, Bing u. a.) in ihrem langen Verlauf mehrfach auf dem Querschnitt getroffen sein kann, während bei der Kinderlähmung der auf dem hier besonders gïnstig sich verteilenden Blutwege zugetragene Infektionsstoff ganze Einheiten befällt.

Bei den leichten und mittelschweren Fällen von Spina bifida occulta mit progredienter FuBdeformität haben wir also in erster Linie die krankhaft veränderte rezipierend-regulatorische Tätigkeit des Marks zu berücksichtigen. Aus den immer wieder in wechselnder Weise anzutreffenden klinischen Symptomen der erhöhten Muskelrigidität, des positiven Babinskischen Phänomens und anderer gleichwertiger Reflexerscheinungen müssen wir diese Veränderung als eine Herabsetzung der Toleranzorenze des Marks auffassen. Vieles von den bisher erwähnten Verhältnissen an Mark und Markkanal läßt sich in diesem Sinue deaten, wemn auch für manche Erwägung der pathologisch-anatomische oder pathologisch-physiologische Beweis fehlt. Es können durch die herdförmigen Defekte die kortikospinalen Hemmungsbahnen in ihrer Wirkung herabgesetzt oder auch ganz aulgehoben seiu. Gesunde Nervenfasern, die durch gestörte Gebiete ziehen, dürften wohl häufig einwirkenden Reizen ausgesetzt sein, zumal wenn die Markscheide fehlt und der empfindlicke Achsenzylinder entblößt in dem vielleicht narbig verhärteten Gewebe ruht. Hier liegen meines Erachtens die Angriffspunkte jener still wirkenden Kräfte, auf die Duncker hinweist, wenn er von den ,.differenten Entwichlungstendenzen des dysplastischen und des normalen Gewebes" spricht. Und hier haben wir auch den schädigenden EinfluB jener unphysiologisclen Fixierung des Conus medullaris und der sich 
als Geschwulst präsentierenden lipomatōsen Ausfüllung zwischen Mark und Kinalwand zu suchen. Weiterhin kinn es nicht verwunderlich sein, daß an einem Ful die ïblen Folgen dieser Veränderungen in dem seine Funktion regeluden Apparat dann in erhöhtem Maße sich zeigen, wenn durch gesteigerte Inumspruchnohme des Fußes die um ein Vielfaches vermehrten zentripetal cinströmenden Reize ihre anormale Auswirkung in ebenso verstärktem Grade zur Geltung bringen. Wie wichtig und wirksam dieser rezipierende Regulationsapparat für den geordneten Ablauf rein motorischer Vorgänge ist, möge noch ein Beispiel illustrieren. Edinger erwähnt als solches die ,steifen" Finger im Winter. „, Die Muskeln können sich offenbar nicht normal kontrahieren, wenn sie von den Sehnen- und Gelenkenden her nicht regulierende Empfindungen erlangen kömen". Auch der ataktische Gang der Tabiker, deren Muskelsinn erloschen ist, gehört hierhin. Obwohl zwar ein Unterschied besteht : beim Tabiker fehlt der zuströmende Reiz. beti der Spina bifida occulta dagegen trifft er anf ein erhöht reizbares Mark und gelangt zu ungendneter Auswirkung. Zuletzt such könmen auch Reize in dem Mark selbst entstehen. die dann zu anormalen Sipannungszuständen in der Muskulatur führen. Sie können ihren Ursprungr haben in der ,,differenten Entwicklungstendenz der Gewebe ", in der Arretierungr und in der Finwirkung der Fettgeschwulst. Dies wären Steigerungsgrade in der Wirkung der genannten Faktoren, die in ihren höchsten Graden durch Druckwirkung usw. zu fortschreitenden Zerstörungen im Mark und deutlich zunehmenden Ausfallserscheinungen führen. Eine solch weitgehende Schädigung des Rückenmarks lïßt sich aber in den meisten Fällen der Spina bifida occulta nicht nachweisen, so daß ich den Unterschied zwischen den beiden ersten Graden und dem letzten fast als wesentlichen und nicht rein graduellen ansehen möchte.

Wir finden mun auch mit Leichtigkeit Gründe, warum die Fubverbildung progredient ist und mal früher, mal später erst in Erscheinung tritt. Eine Zuxammenstellung des Zeitpunktes, an dem nach den Angaben der Eitern usw. die Fulsverbildung begonnen haben soll, nach eigener Beobachtung und Mitteilungen anderer Autoren (Duncker, Bibergeil usw.) ergibt, dals bestimmte Lebensalter in hervorragendem Maße den Ausbruch einer Fußverkrüpplung zu beginstigen scheinen. Wir haben zunächst Kinder. die eine Mißstaltung eines oder beider Füße mit zur Welt bringen. Ist der Pes equino varus durch die vielfach beschuldigte Raumbeschränkung (Hohmann, Fränkel, Turner u. a.) oder durch eine fehlerhafte Keimanlage der Extremitait selbst bedingt, so scheidet er für unsere Betrichtung auch damn aus, wenn er mit einer Spina bifidi occulta vereint ist. Unser Interesse gehört ihm nur damn, went er in voller Abhängigkeit von der Wirbelmißbildung entstanden ist. Liegt es im Bereich der Möglichkeit, claßs schon im nterinen Dasein die gleichen Vorgänge Finfluls gewinnen, die sonst in späteren Lieben als Ursache der Verkzrïppelungr beschuldigt werden müssen? Im Zustand der ersten Entwicklung wachsen die Gewebe aus sich heraus und bilden ihre form nach der erblich mitgegebenen Veranlagung. t'ber den /eitpunkt. da das Wirken selbständiger, immanenter Bildungskriäfte mehr und mehr zugunsten der trophischen Wirkung funktioneller Reize zurüchtritt, sagt Roux: .:Die Zeit, zu welcher für jedes Gewebe und in jedem Organ die Periode des embryonalen Lebens aufhört und die des Reizlebens beginnt, ist wahrscheinlich für jeden Teil verschieden. Wir zeigten, 
daßs die Gefäße. die Knochen und die Bindegewebsbildungen ihro normale Gestalt wahrscheinlich ïberhaupt nicht ganz selbständig im Embryo ausbilden". Nach Roux liegen also bei der Formung des skelettes zwei Faktoren im Kampf: Vererbtes Wachstum und durch Funktion erforderte Anpassung. Beide werden ja im allgemeinen Hand in $\mathrm{Hand}$ gehen und zur Wohlgestaltung des werdenden Menschleins beitragen. Weist aber die Funktion erhebliche S'törungen auf in der Weise z. B.. daß ein Cherwiegen bestimmter Haltungsanomalien oder bestimmter einseitiger Bewegungen vorliegt), so muß, wenn diese Funktion schon im Cterus sich in erheblichem Maße auswirkt, die der Form entsprechende Formung darunter leiden. da die dem Stützgewebe innewohnende Gestaltungskraft von der Gewalt des funktionellen Reizes zuruickgedrängt und vielleicht ganz ausgeschaltet wird. Was Roux in phylogenetischem Sinne sagt: „Indem nämlich unter der Einwirkung der Reize eine Züchtung entsprechender Reizsubstanzen und Reizformen stattfindet, geht die embryonale Indifferenz and selbständige Erhaltungsfähigkeit der Teile mehr und mehr verloren," hat meines Erachtens auch Gültigkeit in der Ontogenese: Wenn - auch zu einer Zeit, da innere Formungskraft noch Geltung hat - die trophische Wirkung funktioneller Reize in erheblichen, vielleicht steigenden Maße aktiv wird, geht die vererbte Wachstumseigenschaft zurück und tritt die funktionelle Anpassung niehr und mehr in den Vordergrund. - Soll es aus diesen Grïnden noch während des fötalen Lebens zur Ausbildung einer Fußdeformität kommen, so muß die gestörte Funktion schon recht frühzeitig und recht lebhaft wirksam werden. Frühzeitige, heftige und häufige Kindsbewegungen. die durch irgendwelche pathologischen Zustïnde der Schwangeren oder des Fötus bedingt sein können, in diesem Sinne auch Raumbeschränkung (uicht als mechanisches. den Fuß pressendes Moment aufgefaßt, sondern in der Weise, daß der Föt gegen Teile der Gebärmutter tritt oder etwa an der Nibelschnur zerrt usw.) und endlich ohne dies - auch Reizzustünde im mißbildeten Mark (das als solches wiederum für Störungen etwa der Blutzirkulation usw. besonders empfindlich ist), die zu Spasmen und Krämpfen führen, sind Vorgänge, die zur Ausbildung einer Fußdeformität ante partum führen können. Allerdings ist die Einwirkung der gestörten Funktion auf den Fuß nur von beschränkter', verhältnismäßig kurzer Zeitduer, so da $B$ die oft gerade hochgradigen angeborenen Deformitäten wohl in der Mehrzahl der Fälle nicht allein aus jener herzuleiten sind. Andererseits wieder muß dock erwähnt werden. da $\$$ der junge, in lebhaften Wachstum befindliche fötale Knocken sich schneller der Funktion anzupassen vermag als etwa der Knochen eines Erwachsenen (Beispiele dafür liefert in Hülle und Fülle die Klinik der Frakturen, wenn man die Heilungsund Lmformungsprozesse bei Kindern mit denen der Erwachsenen vergleicht).

Ein zweites Maximum bringt das dritte Lebensjahr, ein drittes, gleich hohes, das siebte Jahr. Ich stelle beide zusammen, da sie die gleiche Lirsache haben. Es ist die erhöhte Inanspruchnahme der Beine. Das dreijährige Kind hat vor ein bis zwei Jahren Laufen gelernt und gebraucht nun in wachsender Häufigkeit und Ausdauer seine Gehwerkzenge. Der ursprünglich wohlgeformte Fuß gestaltete sich unter der gestörten Einwirkung der Muskelkräfte langsam in zunehmender Stïrke um. bis der Mutter beim Baden oder sonstwie die Ungleichheit der Füße ihres Lieblings auffällt. Wir müssen also den Beginn der Deformität 
$11 \mathrm{~m} 1 / 2$ bis 1 . Tahr zurückdatieren. Fhenso ist es bei dem Kinde, das seit seinem fünften bis sechsten Lehensjatr zur s'chule mußte, nun täglich vielleicht einen weiten Weg zu machen hatte und beim spiel mit den Kameraden seine Beine oft recht erheblich anstrengte. Zwei Auszüge aus den Krankengeschichten der hiesigen Klinik seien eingefügt, weil sie in klarer Weise das Gesagte bestätigen. Schn. Paul, Zwillingskind. 5 Jahre alt. - Gravidität und Partus verliefen normal, obwohl Mutter Pruripara war. Paul kam als zweiter. Folgte dem Bruder gleich nach. Wog $\mathbf{4}_{14}^{1}$ Pfund: der Bruder Peter $\mathbf{4}^{1} / 2$. Beide entwickelten sich gut. Paul lernte mit $1^{1}: 2$. Jah ren Laufen. Gang war ganz nornal. Im Alter von zwei .Tahren zum ersten Nale Lungenentzündung. Nach ungefähr einem Jahre wiederum schwere doppelseitige Pueumonie, stand aber schon nach sechs Wochen wieder auf. In dieser Periode nun bemerkte die Mutter, dafs der Junge das rechte Fïßcten schief aufsetzte und glaubte (spontane Äußerung der Mutter!). daß der. Tunge zu früh nach der schweren Krankheit aufgestanden und daher noch zu schwach gewesen wäre. Sehr bald erkrankte der .Junge an Masern und im Anschluß daran abermals an doppelzeitiger Lungenentzünduug. Er lag nun viel zu Bett und hatte sich erst im Sommer 1919 (etwa 4/2. Jahre alt) wieder vollständig erholt, so da $\beta$ er in diesen Sommer immer auf war, herumlief und spielte. Gegen Ende dieses Sommers trat (wiederum spontane Außerung der Mutter!) eine schnellere und bedeutendere Verschlimmerung des rechten Füßchens ein. so daß er dieserhalb Anfang 1920 zur Klinik gebracht wurde. - Ar. Peter-Paul., geb. 29. Tuni 1905. Geburt normal. Wurde im dritten Lebensjatr $r$ wegen beiderseitigem Senkfuß vierzehn Tage hindurch mit Gipsverbändclen behandelt und trug von dieser Zeit an während einiger . Tahre Einlagen. War ohne Peschwerden. Irgendeine Verbildung an den Fiußen war nicht zu bemerken, der Gang war korrekt. Als Ar. sechs Jahre alt war. wechselten die Eltern die Wohnung. Während der Junge auf der Etagenwohnung in der Großstadt keine Gelegenheit hatte, im Freien zu spielen (ein Garten war nicht vorhanden. der Schulweg war sehr kurz - besuchte erst seit einem Monat die Schule), mußte er nun täglich einen weiten Weg zur Schule machen und trieb sich vom Morgen bis zum Abend im Freien herum. Finige Zeit später fiel der Wutter beim Baden des Jungen eine Verkrümmung des rechten Fußes auf: der First war höher als am linken. Früher war solckes nicht bemerkt worden, obwohl die Füße wegen der früheren Plattfußanlage von den Eltern beobachtet wurden. Im Laufe der nüchsten Jahre bog sich der Fuß, wie der Vater sagte. immer mehr nach oben. Auch wurde zuletzt, seit etwa drei Jahren. der Gang leicht hinkend. Schmerzen hat der Junge im Ful nie verspürt.

Es ist nun nicht so sehr die vermehrte Funktion, sondern die dabei unausbleiblich eintretende Ermüdungsphase oder tberanstrengung, die von schädlichen Folgen für den Fuß ist. Fin Schulkind mag nach der Zeit. gemessen vielleicht mehr der Ruhe pflegen am Tage als das Spielkind; es wird aber sicherlich eher Veranlassung haben, in einer Zeiteinheit größere Anforderungen an seine Gehwerkzeuge zu stellen als das spielende Kind. das meist im Kreise gleichgearteter Freunde oder gar allein nur das tut, was ihm lieb und bequem erscheint. und daher theranstrengungen im allgemeinen meidet. Wird so ein krankes Fübchen. dem man bisher allerdings noch nichts Krankhaftes ansah, mehr belastet, als der ihm durch Muskeln. Bänder und Knochen gewährten 
Kraft entspricht, sind durch längere oder heftigere Inanspruchnahme die durch Terrung an den Bandverhindungen und den Gelenkkapseln und die durch den Druck und die Reibung der Gelenkflächen gegeneinander ausgelösten zentripetalen Reize gesteigert, so wird das erkrankte Mark mit einer über das richtige Verhältnismaß hinausgehenden Reaktion antworten. Die Folge sind erhöhter 'Tonus oder gar Spasmen in den letroffenen, vom defekten Regulator beherrschten Muskelbezirken, die auch noch nachwirken werden, wenn der äußere Faktor der gesteigerten Funktion schon wieder in Wegfall kommt, aber die Reizerscheinungen in den gezerrten und gedrüickten Gelenken erst langsam abklingen. Diese Zustïnde summieren sich entsprechend dem wiederholten Einwirken ähnlicher Vorgänge. Die Spasmen werden zu Dauerspasmen mit ihrer bekannten Folge der untritiven Schrumpfung und weiteren sekundären. Verïnderungen am skelett. Muskehn, die in einzelnen Teilen gelähmt sind, können Arbeiten bis zu einer gewissen Höhe leisten, die jedoch unter der Leistung des gesunden Muskels zuriickbleiben. Wird jedoch mehr won dem Muskel gefordert - twa das, was dem gesunden entsppicht. so ist das G]eichgewicht zwischen der Gröbsder Funktion und der Größe des sie vollziehenden substrates (Roux) gestört, and wir haben das Bild der schidigenden theranstrengung. Auch dieser Faktor bewirkt. daß teilweise schlaffe Iähmung eines Muskels erst damn besonders in Erscheinung tritt. wenn er ïber das ihm verbliebene Kräftemaßs hinaus be:dnsprucht wird.

Bei e rhöhter rezipierend-regulatorischer Tätigkeit des Markes an zirkumskripten stellen und bei teilweiser schlaffer Lähmung eines Muskels treten die schädlichen Eolgen erst dinn zutage, wenn die Vollziehung der Funktion eine gewisse Grenze übersteigh Interhalb dieser Grenze kann das Krankheitsbild latent bleiben.

Das zweite und dritte Lehensjahr und das erste schuljahr bieten mit ihrer erhöhten Anforderung au die 'Tätigkeit der Gehwerkzeuge Gelegenheit genug, diese Grenze der Latenz zu überschreiten. Ich glau he hiermit eine plausible Erklärung für das gehäufte Auftreten der bezüglichen Fußdeformitäten in den beiden Altersstufen gefunden zu haben. Fast die Hälfte aller mit Spina bifida occulta vergesellschafteten progredienten Fußverbildungen nehmen ihren Anfang in diesen . Tahren.

Einen weiteren bestätigenden Beitrag liefern jene Fälle, bei denen die Verbildung erst während der Dienstzeit beim Militär, also etwa im 18. Lebensjahr. manifest wurde. Ich will auch hier aus zwei Krankengeschichten das dieshezügliche kurz anfïgen: Schl. Johann, 21 Jahre alt. Im zehnten Lebensjahr bemerkte Patient, daß sich der linke Fußs schief stellte. Hatte aber keinerlei Beschwerden. Die Verbildung wurde wohl im Laufe der Tahre deutlicher, aber so eminent langsam. dab Patient noch im Alter von $14 \mathrm{Jahren}$ erfolgreich an Wettläufen teilnahm. Wurde mit I8 Jahren zur Artillerie eingezogen, nachdem er vorher wegen häuslicher Verhältnisse vom Dienst frei geblieben war. Erlitt sehr bald eine schwere Verletzung an der rechten Hüfte, die mit Versteifung und starker Verkürzung heilte. War nach Ausheilung der Wunden als Arbeiter auf einer Brikettfabrik tätig. In dieser Zeit aber verschlimmerte sich der linke Fuß sehr schnell und traten Beschwerden hinzu, die ihn schließlich an der Arbeit hinderten. Kam mit hochgradigem Pes equino varus excavatus 
zur Klinik. - Ver. Matthias, 23 Jahre alt. Trat mit siebzehn Jahren als Freiwilliger bei der Marine ein. Hatte bisher nie Beschwerden von seiten seiner Füße. Gang soll glatt und gleichmäßig gewesen sein. Erst im zweiten Jahre des Dienstes verschlechterte sich das Gehvermögen. Wurde zweimal ohne Bewserung operiert., Hat jetzt ausgesprochenen Klatenhohlfuls links.

Eine weitere Erklärung dieser Fälle ist nach dem oben Gesagten nicht. mehr notwendig. Duncker und Bibergeil bringen ganz ïhnliche Krankheitsbilder.

Ein Maximum, das im elften Lebensjahr liegt, schien mir zunächst schwer zu begründen und zu deuten. Hier konnte der oben beschuldigte Faktor der vermehrten Funktion nicht recht in Frage kommen; es mußte also nach anderen Momenten gesucht werden. Ein solches ist meines Erachtens das Geset\% der Wachstumsperioden im kindlichen Alter: Perioden der Streckung wechseln nit denen der Fïlle ab. Nach Stratz, der sich auf andere Pädiater beruft. haben wir folgenden Turnus: Erste Fiille rom 1. bis 4. Jahr. - Ersto Streokung rom 5. bis 7 . Jahr. - Zweite Fülle vom 8. bis 10. Jahr. - Zweite Streckung vom 11. bis 15. Jahr - und dritte Fülle oder Reifung vom 15. bis 20. Lebensjahr. Das eine Mal eine reichlichere Anlagerung von Fettgeweben, das andere Nal eine plötzliche Streckung wohl vornehmlich des Skelettes (beschuldigt man doch beim Zustandekommen des Schlatterschen Krankheitsbildes ein Mißverhältnis zwischen Knochenwachstum und dem der Muskulatur als begünstigendes Moment der Lösung der Tuberositas!), sie können auch leicht. das von unphysiologischer Fessel gehaltene Mark und das von vermehrtem Fettgewe be umschlossene Nervensystem beeinflussen, und zwar im sinne einer Erregung desselben! Gerade das erste Moment mag hier an Bedeutung gegeniiber anderen gewinnen. Die erste Streckung von 5 bis 7 wïrde also ebenfalls ihren Teil zu dem hohen Maximum den sechsten bis siebten Lebensjahres beitragen.

Wahrscheinlich spielt auch der Beginn der Pubertät eine nicht unwesent liche Rolle in der Erhöhung der Erregbarkeit des Markes. Ungeklärte Vorgänge und Wirkungen innerer Sekretion mögen hier die Ursache abgeben.

Alles in allem haben wir als erste Ursache der fortschreitenden Miß bildung die kongenitalen Veränderungen am Mark anzusehen, die sich aus zwei Komponenten zusammensetzen: (Bei den leichten Fällen) in erster Linie Herabsetzung der Toleranzgrenze beim duswirken zentripetal einströmender Reize, in zweiter Linie glatte Ausfallserscheinungen haptsächlich im motorischen Gebiet, wenigerim sensiblen. Diese krankhaften Zustände können mehr oder weniger lange Zeit hindurch latent bleiben. In einer über ein gewisses Ma $B$ gesteigerten Funktion haben wir den wichtigsten Faktor, der bei der Sichtbarmachung derkongenitalen Markmißbildung durcheine progrediente Fußdeformität wirksam ist. Dieser wird ergänzt durch Einflüsse der atypischen Fesselung und Fettumhüllung des Marks und schlieBlich noch durch Wachstumsdifferenzen innerhalb des Rückenmarks selbst gesteigert. Alle drei können auch in ein gewisses Abhängigkeitsverhältnis zueinander treten. So kann z. B. durch eine infolge der , Streckung" zunehmende Zerrung des Marks eine Steigerung seiner Erregbarkeit bedingt 
werden, so daß uun erst die Funktion die ,Latenz"grenze ïberschreitet. Da die klinischen symptome eine scharfe Trennung dieser primären und helfenden Crsachen nicht ermöglicht, so bleibt als erstes Erfordernis einer rationellen Therapie die Inspektion in loco, d. h. die Eröfnung des Lumbosakralkanals mit nachfolgender Entfernung einer etwa vorhandenen Eessel oder einer Fettgeschwulst. Dieser Eingriff vermag schon für sich eine Besserung und gar Heilung zu zeitigen.

In der bis heute vorliegenden Literatur begegnet man mit wenig Ausnahmen immer der gleichen Art von Fußmißbildung, die sich zur Hauptsache als Kombinationen der drei Typen: Pes equinus, Pes varus, Pes excavatus darstellt und vielfach mit Klauenstellung der Zehen verbunden ist. Da muß sich einem die Frage aufdrängen, ob sich diese Gleichartigkeit aus dem Ursprung und der Verteilung der Nerven und einem Lieblingssitz der Markmißbildung erklären läl3t oder ob nicht vielleicht noch andere Verhältnisse dabei von Bedeutung sind. Wir werden diese Frage weiter unten zu beantworten suchen. da sie sich nur in Verbindung mit den Ergebnissen der Untersuchung der Muskelmechanik des Fußes eingehender beantworten läßt. Es wird also später auf die Zusammensetzung der Jerven aus ihren einzelnen Wurzelkomponenter zurückzukommen sein; doch möchte ich hier schon betonen, daß die angebliche Gleichartigkeit wohl nicht ganz in dem Maße, wie sie sich aus der heutigen Literatur ergibt, zu Recht besteht, denn auch das, ,quasi" Gegenstück zu diesen Verbildungen: der Plattfuß wird sicher mehr, als bisher geschehen ist, aus der gleichen kongenitalen Mißbildung herzuleiten sein. Andeutungen finden sich bei manchen Autoren (Rendu et Verrier, Fuchs, Beck u. a.). Ich möchte also noch zwei weitere Typen hinzufügen: den Pes planus und den Pes valgus mit ihren Kombinationen. Es liegt allerdings vor allem in dem statischen Moment der Genese des Sienkfußes eine große Schwierigkeit, genau zu umgrenzen, wie weit derselbe als reine Folgeerscheinung der Spina bifidia occulta anzusehen ist. Darum wird es nur selten gelingen. einwandfreie Fälle aufzufinden. Ich kann leider nicht mit genïgend geklürten Fällen aufwarten, obwohl unter den hier beobachteten Fällen einige Male eine einseitige Pes equinovarus deformität mit einem gegenseitigen Pes planus vereint war. Ich weise auf den schon erwähnten Fall Ar. hin und führe noch den Zwillingsbruder des ebenfalls schon zitierten Schn. Paul an. Dieser hatte fast die gleiche Knochendeformität (Spalt im Bogen des letzten Lendenwirbels) und beiderseits leichten Pes plano valgus. Bei dem Bruder lag der Defekt im ersten und zweiten Sakralwirbel und zeigte sich eine Unregelmäßigkeit im Bogen des fünften Lumbalwirbels. Die unbestreitbar dominierenden Typen sind aber die drei erst genannten. Dies wird sofort verständlich und erklärlich, wenn wir die Muskel- und Gelenkmechanik beachten und daran festhalten, daß die Herabsetzung der Toleranzgrenze beim Auswirken zentripetal einströmender Reize das $A$ und $\Omega$ in der Genese der progredienten Fußdeformität bei der Spina bifida occulta bildet. Wir werden uns nun der Besprechung dieser zwei Faktoren zuwenden, nachdem wir zuvor noch kurz die Veränderungen in den peripheren Nerven gestreift haben. Wenige Worte genïgen, da die Pathologie der Nerven in so hervorragendem Maße von den Veränderungen, namentlich den reinen Defektbildungen im Mark abhängig sind und ihnen eine selbständige Bedeutung 
nicht zukommt. Die mit ihren Wurzeln aus den geschädigten Rückenmarksabschnitten entspringenden Nerven sind vielfach dünner und auf dem Querschnitt anders begrenzt als normalerweise; auch zeigen sie in gleich großem Bildfeld weniger Nervenfasern als die gesunden Nerven. Es laufen also durch einen solchen Stamm, z. B. den Ischiadikus weniger nervöse Leitungshahneu. so daß in derem Verbreitungsgebiet sich größere und kleinere Distrikte finden miissen. die gar nicht oder doch nur unvollkommen von dem Nerven versorgt werden. Auf diese Weise kommen die klinisch kaum nachzuweisenden disseminierten Teillähmungen einzelner Muskein zustande.

Das für die Bewegungsmöglichkeiten des Fußes bedeutungsvollste Gelenk ist das Talokruralgelenk, weil sein Drehungswinkel um ein Vielfaches den der anderen Fußgelenke übertrifft. Der maximale Ausschlag beträgt nach Fick zirka $5 \tilde{5}^{\circ}$. Davon entfallen, wenn man als Ausgangspunkt einen Fußunterschenkelwinkel von $90^{\circ}$ annimmt, auf die Dorsalflexion $15^{\circ}$ und auf die Plantarflexion $40^{\circ}$. Die Mittelstellung liegt also bei $103^{\circ}$. Diese Stellung entspricht meines Erachtens der Ruhestellung des Fußes und wird auch sicherlich im Leben längere Zeit hindurch innegehalten als die von $\mathbf{F}$ ischer mit Normalstellung bezeichnete Haltung in einem Winkel von 90․ Beim Gehakt treten in der Phase eines Schrittes beide Stellungen alternierend auf; doch ist die Teitdauer der Equinusstellung länger als die der Normalstellung und ihrer steigerung in dem Augenblick, da sich zur Vorbewegung des Rumpfes das aktive Bein aus seiner senkrechten Stellung in eine nach vorne geneigte, schräge Stellung dreht (Landois-Rosemann). Demonstrieren kann man dies am einfachsten an einer Serie von Momentphotographien, die, in gleichen Zeitintervallen aufgenommen, auf der Mehrzahl der Finzelbildchen eine Spitzfußstellung zeigen und nur etwa zu drei Siebtel den Fuß im rechten Winkel oder in noch stärkerer Dorsalflexion festgehalten haben. (In den Gängen der Düsseldorfer Kunstakademie finden sich Serien von Momentaufnahmen aus dem Sportleben, die zum Teil recht schön das Gesagte illustrieren.) Ferner wird in der Ruhe, im Schlaf wohl ausnahmslos eine mehr oder weniger tusgesprochene Spitztußstellung innegehalten. und selbst beim Stehen und erst recht beim Sitzen werden die Füße durch Firnahme der Schrittstellung resp. Hängenlassen in eine Plantarflexion von etwa $103^{\circ}$ gebracht. Ein völlig entspannter Fuß stellt sich in leichte Spitzfußstellung, wie man im Bade und oft selbst bei ungehemmter Einwirkung der Schwerkraft in Bauchlage an dem frei herabhängenden FuB nachprüfen kann. Ein stundenlanger Varsch ermüdet den FuB nicht so sehr wie ein gleich langes Stehen, weil eben die rechtwinklige Haltung die unphysiologischere ist und eine gewaltige Arbeitsleistung von einer begrenzten Muskelgruppe fordert, während beim intermittierenden Zehenstand (Engels) sich die gleiche Arbeit auf fast alle Unterschenkel-Fußmuskel verteilt. Die Drehbewegung im Talokruralgelenk, verläuft nun nicht genau in der Achse des Unterschenkels, sondern ist bei der Plantarflexion mit einer leichten Anziehung und Adduktionsbewegung des vor dem Gelenk gelegenen Fußabschnittes verbunden. Das Gelenk selbst gibt einige Anhaltspunkte dafür. Während an der medialen Seite der Talus und mit ihm der Kalkaneus durch die breite Bandmasse des Ligamentum deltoideum (Spalteholz) mit dem Malleolus medialis verankert ist, ziehen auf der lateralen Seite drei dünne, 
isolierte Bandstreifen zur Fibula hin. Hier ist also die Fixation eine geringere als an der Innenseite und dementsprechend ist auch die seitliche Gelenkfläche der Trochlea tali, wie am Skelett klar zu sehen ist, größer und besser ausgebildet an der lateralen als an der medialen Seite. Wir haben also neben der horizontalen Achse noch eine vertikale, die durch den Malleolus medialis geht. Es ist dadurch die Möglichkeit gegeben, daß der laterale Rand des Talus sich um diese Achse drehend zehenwärts resp. fersenwärts verschiebt. Dieser letzten Drehung ist aber durch die Gestaltung der Gelenkflächen eine frühe Grenze gesetzt; da nämlich die laterale Gelenhfläche der Talusrolle verjüngend von zehenwärts außen nach fersenwärts innen gerichtet ist, so wird die Außendrehung des Vorderfußes um die Vertikalachse sehr bald gehemmt werden, da der sich verlängernde Querdurchmesser der Trochlea sich mehr und mehr in die Malleolengabel einklemmt. Bei Betrachtung des Sprungbeines von oben ergibt sich das Gesagte von selbst. An sogenannten ,, hnochigen" Füßen kann man vor und etwas unterhalb des Malleolus externus den Processus lateralis tali abtasten und durch seine Bewegung zehenwärts bei stärkster Plantarflexion am Lebenden die Drehung um die vertikale Achse im oberen Sprunggelenk demonstrieren. Deutlicher als dieser Knochenvorsprung am Talus ist der tiefer gelegene Processus trochlearis calcanei zu fühlen. Dieser macht ebenfalls bei Plantarflexion eine deutliche Wanderung' zehenwärts mit und tritt außerdem tiefer (= plantarwärts). Letztere Bewegung entspricht der Unterwärtsrollung des äuBeren Fußrandes im Gelenk zwischen Talus und Kalkaneus, die weiter unten besprochen wird. Zahlreiche Vergleiche haben ergeben, da $B$ die Zehenwärtsverlagerung des Processus trochlearis calcanei fast eindeutig mit der gleichsinnigen Bewegung des Processus tali lateralis ist. Wir haben also auch in der Bewegung dieses Knochenvorsprunges am Lebenden einen Beweis für die Möglichkeit der genannten Bewegung im oberen Sprunggelenk. (Straßer rerlegt diese Bewegung zum wesentlichen in die unteren Sprunggelenke als Begleiterscheinung der Längsrotation des Fußes.)

Das Gelenk zwischen Kalkaneus und Talus besitzt eine geringe Bewegungsbreite, hat aber doch als Bewegungsrichtung bestimmendes Gelenk eine gewisse Bedeutung. Die Achse, um welche die ausgiebigsten Bewegungen statthaben, hat eine Richtung von fersenwärts-lateral nach zehenwärts-medial und ermöglicht ein Tiefertreten des distalen Kalkaneusendes mit dem Os cuboid. Es senkt sich somit der äußere Fußrand und schiebt sich gleichzeitig medialwärts unter die medialen Knochenreihen.

Im Chopart läuft die Hauptachse von lateral-plantarwärts nach medialdorsalwärts, sie bildet mit der Frontalebene einen kaum nennenswerten spitzen Winkel, der medialwärts offen ist oder liegt ganz in derselben. Die Plantarbewegung in diesem Gelenk hat somit ebenfalls eine adduzierende und einwärtsrollende Stellungsänderung des Vorderfußes zur Folge. Dunckè erwähnt das untere Sprunggelenk und das Chopartsche Gelenk als ein physiologisch einheitliches Gelenksystem, in dem iiberhaupt nur Kompromißbewegungen mōglich sind, die bei Plantarflexion in gleichzeitiger Adduktion und Supination bestehen. Das Endresultat ist in beiden Fällen dasselbe, obgleich ich das untere Sprunggelenk nicht mit dem Chopart als physiologische Einheit auffassen möchte, sondern die beiden Gelenke mit Rücksicht auf ihre ver- 
schiedenen Bewegungsachsen trenne, dagegen wohl Chopart und Vorchopart als zusammengehörig betrachte, da für beide die Bewegungsachsen fast in einer Ebene liegen, wenn sie auch einen spitzen Winkel miteinander bilden.

Bei einer starken Plantarflexion im Chopart und Vorchopart bilden Talus, Navikulare und Kuneiformia I. II und III eine mehr oder weniger gekriimmte Bogenlinie und werden daher das Navikulare, das wie ein Keil zwischen Talus und Kuneiformia sitzt. zur Peripherie hindrängen, so daß eine Subluxation dieses Knochens nach dem Dorsum sehr wohl möglich ist. Duncker hält diesen Vorgang für den Entstehungsmechanismus des Hohlfußes für ebenso charakteristisch wie die Senkung und Innenrotation des Navikulare beim PlattfuB. In den hier beobachteten Fällen trat, soweit eine Röntgenaufnahme des Fußes angefertigt wurde (zumeist auf die hochgradigsten Fälle beschränkt), das Navikulare nie über die von dem veränderten Talus und den Kuneiformia bestimmte Bogenlinie heraus, so daß von einer Subluxation des Kahnbeins nicht die Rede sein kann. Selbstverständlich wird es in manchen Fällen von Hohlfußbildung zu einer solchen Verlagerung dieses Knockens kommen, doch ist sie nicht pathognomisch für dieselbe.

Das Lisfrancsche Gelenk gestattet, als einheitliches Gelenk aufgefaßt, nur geringe Bewegung im Sinne der Plantar- und Dorsalflexion, wird aber durch sekundär bedingte zirkumskripte Lockerung der Bänder dem einen wder anderen Metatarsale eine stärkere plantare Einstellung gestatten. Fs tritt dies am meisten bei dem Metatarsale $I$ in Erscheinung.

Aus der Achsenrichtung und Mittelstellung der beideu Sprunggelenke und des Chopart mit dem Vorchopart, in denen sich die ergiebigsten Bewegungen des Fußes zum Unterschenkel und innerhalb seines skelettes abspielen, folgert sich als die natürliche Ruhelage und Mittelstellung des Fu Bes eine leich te Equinovarusstellung. Geht man von der Normalstellung aus, so liegt der größ3te Pewegungsausschlag nach der Seite der Supination, Adduktion und Plantarflexion. Die Verhältnisse in Knochenbau des gesunden, normalen Fußes liegen also für einen Ubergang in die von der Normalstellung abweichende, dem Equino varus excavatus entsprechende Haltung recht günstig. Vermehrung des Fußgewölbes läßt sich am gesunden Fuß, wenn er in stärkste Plantarflexion tritt, inmer nachweisen. Die Senkung der Fußspitze wird nicht allein im Talokruralgelenk bewirkt, sondern kombiniert sich mit gleichgerichteten Bewegungen in den ïbrigen FuBgelenken, soweit solche dort möglich sind, wird also stets mit einer Zunahme der Sohlenhöhlung einhergehen. Nach Duncker beträgt dieses Plus an Plantarflexion 250, beim Zehengang der Tänzerin sogar $50^{\circ}$. In Fachkreisen ist die Erhöhung der Fußwölbung eine allgemein bekannte Erscheinung und manche junge Tanzschïlerin beneidet ihre ältere Genossin um ihren schön ausgebildeten .,Coupier", den sie ebenfalls durch langes und eifriges "Studieren" zu erreichen hofft. Hier selbst vorgenommene Untersuchung am Fuße eines Balettänzers einer größeren Oper brachte insofern ein interessantes Resultat, als der junge Mann an nicht geringem Grade eines Pes planus litt, so daß am belasteten Fuß eine seichte Exkavation des Dorsums von der Talusrolle bis zum Lisfranc sich auf dem Röntgenbild präsentierte und diese dorsale Mulde am belasteten Fuß im extremsten Zehenstand sich noch um et.wa $2 \mathrm{~mm}$ vertiefte. Die ganze Plantarflexion vollzog sich hier einzig 
und allein im Talokruralgelenk. das eine entsprechend ausgebildete, fast halbkreisförmige Gelenkfläche des Talus aufwies. Sicherlich bestand hier schon der Senkfuß bei Beginn des "Tanzstudiums", die Uhungen vermochten aber nicht, die Mißstaltung zu beheben. Dieser Fall wirft ein interessantes Streiflicht auf die Methode Kruckenbergs, der schwere Plattfüße in spitzfubstellung eingipste und dann gehen ließ, damit durch die Körperlast das FulBgewölbe vermehrt und wiederhergestellt würde. Wenn man mit dieser Behandlungsart einen Erfolg sichern will, so muß darauf geachtet werden, daß beim Eingipsen wenigstens ein leichter Grad normaler Exkavation erreicht wird, sonst läuft man Gefahr, daß die Körperlast entgegen der vorgefaßten Hoffnung die fehlerhafte Stellung noch vermehrt. Die Arbeitsleistung der Plantarflektoren und Zehenbeuger, die in dieser stellung das Fußgewölbe rekonstruieren soll, geht bei dorsaler Exkavation und Belastung des Fußes in Spitzfußstellung in der bloßen Stauchung der Gelenkkomponenten gegeneinander verloren.

tber die Mechanik der Zehengelenke ist nicht viel zu sagen. Sie gestatten Bewegungen im Sinne der Beugung und Streckung und können bei Bänder. lockerung und entsprechend einwirkender Kraft in Varus- resp. Valgusstellung treten. ohne daß Umgestaltung der Knochen vorhergehen miißte. Die aus der Kombination von Beuge- und Streckstellung resultierende Klauenbildung. die sich bei den in Frage stehenden Fußdeformitäten so häufig findet. steht in engstem Konnex mit der Wirkungsweise der Muskel und soll mit dieser gleichzeitig besprochen werden.

Wir haben nun die Frage zu erörtern, wie ist der Einfluß des bewegenden Muskelapparates auf das von ihm abhängige System von Gelenken?

Der Triceps surae äberspringt am Fuß zwei Gelenke: das Talokruralgelenk und das Gelenk zwischen Tilus und Kalkaneus. Wenn er sich kontrahiert. muß er auf beide wirken, falls nicht eines der beiden Gelenke durch antagonistische Kräfte fixiert wird. Das ist jedoch nur indirekt möglich, wenn an den verlängerten Gelenkarmen (für das obere Sprunggelenk: der ganze Fuß; für das Kalkaneoastragalusgelenk rornehmlich das Os cuboideum und Hetatarsale IV und V) eine Sperrung eintritt; Kalkaneus und Talus selbst hiben keine weitere Nuskelfixierung gegen den Cnterschenkel. Nehmen wir unbehinderte Bewegungsfreiheit in beiden Gelenken an. so muß bei der Kontraktion des Trizeps gemäß der oben näher beschriebenen Eigentümlichkeit dieser Gelenke eine Plantarflexion mit Unterwärtsrollung des äußeren Fußrandes und gleichzeitiger Adduktion des vor dem Sprunggelenk gelegenen Fußabschnit tes erfolgen (Supination, da die Achse des Talokalkanealgelenkes durch den lateralen Rand des Fersenhöckers geht. Conf. Straßer). Biesalski bezeichnet den Muskel als beträchtlichen Adduktor und Supinator. Für letztere Bewegung beträgt der Ausschlag $21^{\circ}$. Diese Bewegungen erfolgen synchron. wenn der beiden entgegengesetzte Widerstand gleich ist. Das Endresultat der Wirkungsweise des Trizeps, wie ich es aus dem Bau der Gelenke hergeleitet habe, deckt sich ganz mit dem von Duchenne angegebenen, wenn auch in der Erklärung der einzelnen Phasen ein wichtiger Unterschied besteht. Nach Duchenne spielen Unterwärtsrollung und Adduktion sich im Gelenk zwischen Talus und Kalkaneus ab; während nach meiner Darstellung die Adduktion im Talokruralgelenk vor sich geht, wie das Sichzehenwärtsverlagern des Processus tali lateralis 
be:weint. Duncker entwickelt in seiner Arbeit die Ansicht. da B der triarthroidale Trizeps durch die Grenzstellung seiner Gelenkabschnitte mechanisch paralysiert wird. In der Tat zeigt sich hei maximal flektiertem Knie und naximal plantarflektiertem lub die Achillessehne als nur mäßig gespanntes S'ehnenband. Diese itellung ist aber eine durchaus willkürlich gewihlte und tritt heim Alblauf der Funktion des normalen Gehaktes nicht in Erscheinung. Naximale Kniebeugung und maximaler Zehenstand! Zudem ändert sich das Bild sofort, wem man in dieser Stellung einen dorsalflexierenden Druck gegen die Planta pedis ausiibt: Ohne diaß eine Stellungsänderung eintritt, springt sofort die Achillessehne als straffe Saite ror. Cnter natürlichen Verhältnissen tritt somit die Trizepsnuskulatur mit ihrer supinierenden und adduzierenden Wirkung lei Plintiarflexion des Fubes stets in Alition.

Der Peronkeus longus. hinter dem iußeren Knöchel umbiegend. quer durch die Plintil pedis zum Os cuneiforme I und zur Tuberositas ossis metattarwalis I ziehend, soll den Fuß senken und - im Gegensatz zum Trizeps -pronieren. Btides ist richtig: doch ist seine Funktion damit noch nicht erschöpft. Cm uns seine Wirkung klar zu machen, müssen wir ihn in zwej Alschnite zerlegen: a) rom hinteren unteren Rand des Lalleolus externus bis zur Cmbiegungsstelle im Sulcus m. peronaei und b) von diesem bis zu seinen Ansatzpunkten. In der Strecke a) äberspringt er voruehmlich das Talokruralgelenk und das (bopart. Die Beeinflussung des letzteren ist sehr gering, da seine Kraftrichtung fast senkrecht zur Achse dieses Gelenkes steht; seine Kontraktion wird also zu einer Stauchung des Kuboid gegen den Kalkaneus führen. Anders seine Beeinflussung des oberen Sprunggelenkes: hier wird er eine Drehung im Sinne der Plantarflexion bedingen, dazu aber auch eine Rotation um die senkrecht durch den Valleolus internus gehende Achse, d. h. er wird den Vorderfuls abduzieren und so als Antagonist der adduzierenden Komponente des T'rizeps arbeiten. Wenn durch die Wirkung des Trizeps der Processus lateralis tali sich zehenwärts verscholen hat. so wird eine Kontraktion des Peronaeus longus durch Stauchung des Kuboids und den fortgeleiteten Druek gegen den Kalkaneus den Talus wieder zuriickdrehen. Die Strecke a) wirkt also synergristisch mit dem plantarflelitierenden Trizeps und antagonistisch gegen den adduzierenden Trizeps. In letzter Wirkung wird er vom Peronaeus brevis wahrscheinlich ïbstroffen (siehe weiter unten). Ijie Strecke b) ïberzieht die sagittal rerlaufenden Gelenke zwischen Kuboid und Kuneiformia, das Gelenk zwischen Kuneiformia 1 und Metatarsale [ und das Talokalkanealgelenk, wenn man Kalkaneus und Kuboid auf der einen Seite und Talus. Navikulare und Kuneiforme I auf der anderen seite als Einheiten betrachtet. Es ist allerdings hier noch zu bedenken, daß die Bandverbindungen zwischen den letztgenannten Knochen recht locker sind, und daß auch Chopart und Vorchopart durch die Strecke b beeinflußt werden. da der eine Endpunkt an der Lmbiegungsstelle im Sulkus mit der Achse der erwähnten Gelenke zusammenfällt und der andere Endpunkt distal von dieser Achse liegt. Wir haben hier also eine recht komplizierte Wirkungsmöglichkeit. die sich aber einfach löst, wenn man die Tatsache im Auge behält, daß durch Zug der Sehnenstrecke die beiden Endpunkte genähert werden müssen, was durch Kompromißbewegungen in den verschiedenen Gelenken erreicht wird. Nehmen wir die L'mbiegungsstelle am siulkus als fest- 
stehend an, so muß sich hei Kontraktion zunächst der Ansatzpunkt am Metittarsale I diever nïhern, und das geschieht, wenn sich das Metatarsale plantarwärts bengt. Zweitens muß sich der Ansatz am Kuneiforme nühern, das geschieht wiederum durch Plintarflexion im Chopart und Vorchopart die eine Vermehrung des Fußgewölbes, namentlich an der medialen Seite, aber auch infolge der schrägen Achsenstellung dieser Gelenke eine leichte Adduktionsneigung des vom Gelenk distal gelegenen Fußabschnittes bewirkt. und zweitens durch ein Herniederziehen der medialen Knochenreihe, das eine der Wirkung des Trizeps ganz analoge Drehbewegung im Talokalkanealgelenk darstellt. Am geringsten wird der Ausschlag im (hopart und Vorchopart sein, dal wegen der schriigen Richtung der Kraft zur Drehungsebene in diesen Gelenken nur ein Bruchteil derselben zur Geltung kommen kann. Wir haben also für die Strecke b): beugung des Metatarsale I plantarwärts und Rollung des inneren Fußrandes plantarwärts. Diese letzte Bewegung ist - auf die Gelenkachse bezogen als kongruent der durch den Trizeps verursachten Drehung anzusehen. Ist nämlich beim leichten Zehenstand der Ansatz am Metatarsus I durch Druck des Köpfchens dieses Knochens gegen den Boden fixiert so wird die sehr gespannte Sehne des Peronaeus longus in ihrer Gesam theit von der Umbiegungsstelle an Malleolus bis zum Ende auf den lateralen Fußrand (Druckpunkt ist Umbiegungsstelle in Sulkus) wirken und ibn gegen den medialen Rand pressen und somit unterwärts rollen. Fin geradezu klassisches Beispiel fiir die Wirkungsweise des Peronaeus longus brachte letzthin unsere Poliklinik. Es handelte sich um eine poliomyelitische Lähmung des Peronaeus brevis und des lateralen Teiles des Extensor digitorum longus. Der FuB stand in leichter Addnktionsstellung. Das Fußgewölbe war namentlich an der medialen Seite ganz bedeutend verstärkt. der Großzehenballen der Ferse sehr genähert. Dazu geringer Grad ron Pes equinus. Bei der Operation zeigte sich die Sehne des Peronaeus longus gewaltig hypertrophiert, sie imponierte in ihrer Größe wie eine Achillessehne bei einem fast gleichaltrigen Kinde; die Sehne des Peronaeus brevis war dünn und zerfatert. Die Aponeurosis plantaris geschrumpft. Fon einem lateralen Schnitt aus freigelegt wurde die Sehne des Peronaeus longuw an die Stelle des Peronaeus brevis verlagert; dabei zeigte sich, daß allerdings die Anheftung bei plantarer Einstellung des Fules leichter gelang, da die abgeschnittene Sehne bei maximaler Dorsalflexion, trotz gleichzeitiger Abduktion zu kurz war. In diesem Falle kein Fehler, da das Bein reichlich $21 / 2 \mathrm{~cm}$ verkürzt war. Teh erkläre mir das Zustandekommen der Deformität folgendermaßen: Nach dem Ausfall des Peronaeus brevis berührte der Fuß heim Aufsetzen auf den Boden diesen zunächst nur mit dem äußeren Rand. Die Folge war eine, wenn auch nur vorübergehende, falsche Belastung der Fußgelenke. Von diesen aus zentripetaler Reiz, der eine Korrektur der schädlichen Stellung bewirken sollte. Der Extensor digitorum versagte zum Teil, der Peronaeus longus, der ebenfalls bei der Abduktion mitwirkt. mußte die Arbeit allein übernehmen. Üm aber einen wesentlichen Einfluß in Richtung der Abduktion auszuüben, mußte er sein äußerstes Maß an Kraft hergeben; er zog also mit seiner ganzen Kraftentfaltung die Ansatzstellen am Metatarsus I und Kuboid fersen- und lateralwärts; aber es gelang ihm doch nicht, entgegen der Wirkung der adduzierenden Muskelkräfte, den Ausfall des Peronaeus brevis zu paralysieren. 
Die Folge war eine zwar nur leichte Adduktionsstellung des Fußes, vor allem aber eine Vermehrung des Fußgewölbes. Das Wesentliche in der Wirkung des Peronaeus longus ist das Herabziehen des Großzehenballens und des inneren Fußrandes, die Plantarflexion und - am geringsten - die Abduktion. Seinen Bewegungen ist als eine Art Resultierender eine Verstärkung des Fußgewölbes eigen, die sich bei gleichzeitiger Funktion des Trizeps am dentlichsten zeigen wird, da dann das Fulggewölbe nach Art eines Kartenblattes ron zwei Ecken her gegeneinander aufgerollt wird. (Wäre nicht vielleicht die Dauerkontraktur des Peronaeus longus beim spastischen Plattfuß als ein Versuch der Selbsthilfe des Körpers gegen die durch zu starke Belastung bedingte. in diesem Falle schmerzhafte, Deformierung des Fußgewölbes aufzufassen, und damit die Richtigkeit der Exzision dieser Sehne (mit Peronaeus brevis) als 'Therapentikum in Frage gestellt? Duchenne fand bei isolierter Lähmung des Peronaens longus einen ausgesprochenen Pes planus und konnte Plattfüße durch Kräftigung dieses Muskels bessern. Anders nennt Biesalski den Peronaeus longus einen Plattfußmuskel und zeigt in Abbildung 133 die ausgesprochene Abrluktionswirkung dieses Muskels. Die Einwirkung auf das Metatarsale I wurde bei der Entersuchung nicht berïcksichtigt. Sie scheint mir alser, wie die angeführten Beispiele zeigen, mit zu der wesentlichen Wirkungsweise dieses Muskels zu gehören. Klarer liegen die Verhältnisse bei dem Peronaeus brevis, nach Biesalski dem Plattfußmuskel katexochen. Die Exzision seiner kontratiten Sehne beim Pes planus spasticus kann selbstverständlich zweckmäßig sein; brachte doch in dem oben erwähnten Beispiel sein fast isolierter Ausfall trotz Hypertrophie des Peronaeus longus einen leichten Grad von Pes equino virus zustande.)

Der Peronaeus brevis - hinter dem äußeren Knöchel zehenwärts umbiegend, vor Peronaeus longus gelagert - zieht zur Tuberositas ossis metatarsalis $V$ und inseriert dort ziemlich genau lateral. etwas mehr zum Iorsum hin. Seine Wirkung wird meist mit Plantarflexion und Pronation angegeben. Abweichend davon beschreibt Duchenne den Muskel als reinen Musculus abductorius. der den gestreckten Fuß ein wenig hebt und den maximal dorsalflektierten in die rechtwinklige Stellung bringt. Da die Sehne des Peronaeus brevis. wenn sie angespannt ist. sich deutlich palpieren läß3t (zwischen Valleolus externus und Tub. os met. V), so läBt sich die Funktion des Muskels leicht nach prüfen, ohne die elektrophysiologische Methode Duche nnes in Anwendung bringen zu müssen, der: allerdings den Muskel isoliert zur Kontraktion bringt. Da aber im Leben eine isolierte Tätigkeit des Peronaeus brevis wohl nicht cintritt, so hat die Untersuchung unter gleichzeitiger Mitfunktion anderer Fulsmuskel den Vorzug größerer Natürlichkeit. Einige Hauptphasen seien angeführt: Sowohl bei leichter Beugung wie bei leichter Streckung des Fußes $\left(90^{\circ}\right.$ als Nullstellung angenommen) tritt bei alleiniger Belastung der Zehenballen der Peronaeus brevis nicht in Funktion; erst wenn durch Schwanken eine seitliche Balance des Körpers notwendig wird, springt bei Neigung nach rechts die linke und bei Neigung nach links die rechte Peronaeussehne straff vor. Vorher war jedoch schon oberhalb des Malleolus dort, wo die beiden Peronaealsehnen sich nicht mehr gut roneinander scheiden lassen, ein stark gespannter Sehnenwulst, somit der des Peronaeus longus. der den Großzehenballen niederdrïckte, deutlich zu fühlen. Es zeigt sich sonit, daß der Peronaeus brevis 
fiir die Bewegung im sinne einer Plantarflexion kaum in Frage kommt: jedenfalk spielt or als Fußsenker eine untergeordnete Rolle, i'berrischend scheint davergen das Resultat der Prüfung seiner Tätigkeit bei der Fubhelung: Setzt man dem rechtwinklig gebeugten Fub gegen weitere Dorsalflexion einen energischen Widerstand entgegen, so tritt bei Ausschaltung der Balancebewegung der Peronaeus brevis nicht in Tätigkeit; setzt man alber dem maximal plintarflektierten Ful gegen Hebung einen Widerstand entgegen. so tritt sofort. auch ohne daß seitliche Balance notwendig ist. in den allermeisten Fiilen eine recht kräftige Anspannung des Peronaeus brevis in Erscheinung. Diese dem Verlauf des Peronaens brevis anscheinend widerspreckende Linwirkung auf das Talokruralgelenk erklïrt sich aus der schon beschriebenen Eigentümlichkeit dieses Gelenkes. das bei stärkster Senkung des Fußes eine Zehenwïrtsverschiebung des äberen Fubrandes mit sich bringt und somit den Ansat\%punkt der l'eronaeusbrevikehne von der L'mbiegungsitelle am . Nalleolus extermu entfernt. Der Peronaeus brevis wirkt also in diesem Falle nur indirekt durch Zurückdrehung dex äuBeren Fußrandex (d. i. Abduktion) als FuBheber. Als Hauptfunktion des in Pede stehenden Muskels bleibt die Abluktion und die Näherung des äuBeren Fußrandes an den Malleolus externus, die Pronation. bestehen. Betrachtet man am Standbein den die Lnterlage drückenden Fuls als den fixierten Teil. so ist die vornehmste Aufgabe des Peronaeus brevis. den Unterschenkel gegen den Fub festzustellen in dem Sime, dali er nicht nach der Innenseite umbnickt.

Als Gegenspieler des Peronaeus brevis ist nach Duchenne der Tibialis posticus aufzufassen. Er nennt ihn geradezu den Adductor pedis. Jer Einfluß de Muskels auf das obere Sprunggelenk soll sehr gering sein, so daß man ihn vernachlässigen könnte. In den anatomischen Lehrbiichern wird er als Plintarbeuger und sinpinator des Fubes angegeben. Ferfolgen wir den Verlauf seiner sehne, die hinter dem Malteolus internus umbiegend sich fächerförmig verbreitert und mit ihren Kipfeln am Sirvikulare, an den drei Kuneiformia. am Kuboid und an Hetatarsale II, III und IV inseriert. so wird sofort klar. daß sich seine Wirkung in einer reinen Adduktion des Fußes nicht erschöpfen kinn. Die kräftigsten Ausitrihlungen der rehne gehen allerdings zum Kuneiforme I und zum Narikulare und werden hier namentlich durch den zienslich randwärts gelegenen Ansatz am Kahnbein cine kräftige Adduktion des VorderfuBes bedingen. aber der sechsfich geteilte. fast ebenso starke Rest iikerspringt in gïnstiger Weise Chopart und Vorchopart. Wird also in diesen Gelenken die oben näher beschriebene Plantarabknickung bewirken und auferdem das Talokruralgelenk mit nicht zu unterschätzender Kraft im Sinne der Plantarflexion beeinflussen, da die selinenzipfel an genügend langem Hebelarm angreifen. um gute Wirkung zu erzielen. Die lateril gelegenen Ansatzpunkte am Kuboid und Metatarsale IV lösen zudem auch noch Bewegungen im Gelenk zwischen Kalkaneus und Talus aus. so daß eine Cnterwärtsrollung des üußeren Fußrandes statthat. die sich an Fuß als Supinationsbewegung manifestiert.

Der Tibialis anticus. der mit seiner sehne an die Plantarseite des Ḱmeiforme I und an die Basis des Metatarsale I zieht. beugt in erster Linie den FuB gregen den Unterschenkel. - da er am medialen Fußrand ansetzt, hebt er diesen gleichzeitig und übt (nach Duchenne) auf den Kopf des ersten Mittelful3- 
knochens eine dem Peronaeus longas entgegengesetzte Wirkung aus: läßt ihn ., eine schiefe Bewegung von unten und aulen nach oben und inmen" vollfiihren - und flacht somit das Fußgewölbe ab. Diese letztere, für uns wichtigste Funktion des Tibialis anticus mag bei an sich schon flachen FuBgewölben und bei isolierter Kontraktion des Muskels wohl unzweifelhaft in Erscheinung treten; der Mnskel vermag aber unter nur wenig ge:̈nderten. noch zur Sorm gehörigen Verhältnissen - so parndox das scheinen malg - auch eine Verstïrkung des Fubgewölbes hervorzurufen. Die Beobachtung an normalen, gut gewölbten FüBen und noch besser an Hohlfüben beweist diesen siatz. und auch die genaue Bewertung der Verluufsrichtung der Sehne mit ihren Ansatzpunkten und der Wirkung des Gegenspiels der anderen zum Teil antagonistischen Fußmuskel -- ein Moment. das man beim lebenden FuB nie vernachlässigen dart - stuitzt and bestritigt ihn. Es wurde schon bei Besprechung der Gelenkmechanik erwäbnt, daB in Lisfranc durch zirkumskripte Bandlockerung dem einen oder anderen Metatarmale eine stärdere Plantarflexion ermöglicht wird und daß diese plantare Einstellung am meisten beim Metatarsale I in Erscheinung tritt. da dieses schon an und für sich am wenigsten fixiert ist. Für den Peronaeuw longus ist mach der Lage seiner Sehne an der Sohlenseite des Fubes die Wirkung auf dieses Gelenk klar und eindeutig: sie kamn nur eine plantartlektierende und dadurch das Köpfchen des Metatarsus I niederziehende sein. Die Sehne des Tibialis anticus heftet sich ebenfalls mit einem im allgemeinen dünnen Zipfel an die Plantarseite der Basis des Metatarsale I an. schlingt sich dann aber gleich medialwärts und steigt am medialen Rande des Kuneiforme $I$ und Navikulare zum Iorsum pedis empor, das sie in der Höhe des Gelenkes zwischen Tavikulare und Talus erreicht hat. Hier wird sie durch den unteren schwächeren schenkel des Ligamentum cruciatum cruris festgehalten, um dinn in gleicher Richtung wor dem Malleolus internus in den breiten. kräftigen Tunnel einzutreten, der von dem oberen Schenkel des eben genamnten Bandes und dem Ligamentum transversum cruris gebildet wird. Angriffspunkt am Metatarsale und Drehungsachse des Gelenkes liegen also in einer Linie. die fast mit der Richtungslinie der sehne bis zum unteren schenkel des Ligamentum cruciatum zusammenfällt. Fin durch Zug an dieser sehne bewirkter Ausschlag des Metatarsale wird somit in bezug aut seine Richtung von der Ausgangsstellung abhängig sein. Soll überhaupt eine Wirkung zustandekommeu, so dïrfen die drei Punkte: Ansatz der Sehne (A). Drehungsachse des Gelenkes (D) und Fixierungspunkt unter dem Lig. cruc. (C) nicht in einer linie liegen. sondern mïssen ein Dreieck bilden. Lmschließen nun die Punkte A-D-C einen dorsalwärts offenen Winkel oder liegt. mit anderen Worten. das Gelenk zwischen Metatarsale I und Kuneiforme I tiefer als eine vom Dorsum des Navikulare zur Cnterfläche der Basis des Metatarsale I gezogene Gerade (im Extrem ist dies beim PlattfuB der Fall), so wird bei Kontraktur des Tibialss anticus das Metatarsale I dorsalwärts gedreht, die Ful3wölbung also weiterhin abgeflacht. Ist dagegen der Winkel plantarwärts offen (im Fxtrem ist dies bei Hohlfïßen der Fall). so wirkt der Tibialis ant. insofern gleichartig mit dem Peronaeus longus, als er das Köptchen des Metatarsale sohlenwärts dreht, die Wölbung des Fußes also vermehrt. Diese Deduktion scheint vielleicht eine Art physikalischmechanischer spielerei zu sein, und ich muß gestehen, dals auch mir die Zer- 
gliederung tines lebenden Forganges nach den starren Gesetzen einer toten Hechanik ein Greuel ist. Wie wïrde unser ästhetisches Empfinden um einen hohen Genuß gebracht werden, wenn es gelänge, anch nur die einfache Lebenserscheinung der Lokomotion in ein nüchternes Zahlengewand zu kleiden! Dank. daß dem nicht so ist! Organisches Leben ist auch in seinen simpelsten Betïtigungen nicht in die Formel einer toten Maschinerie zu zwängen! Aber wir müssen leider zur Ërklïrung und Erläuterung solcher Erscheinungen zu Begriffen aus der Mechanik greifen, wenn wir diese in der Natur so unendlich komplizierten Vorgïnge auch nur einigermaßen mit Worten fixieren wollen. I aher verzeihe man mir das Dreieck A D C und äberhaupt schon das Wort .C Crelenkmechanik!" - Nach spalt eholz geht der weitaus kräftigste Teil der Tibialissehne zum Kunelforme und der kräftigste Teil des Peronileus zur Basis cles Metatarsale: wieweit die schwächeren Zipfel dieser Sehnen. namentlich der metatarsale Zipfel der Tibialissehne in der Natur variier-n, ob sie nicht in seltenen Fällen ganz unentwickelt bleiben oder im Gegensatz dazu den dickeren T'eil der Sehnen darstellen können. war mir aus der Literatur nicht ersichtlich. Doch lege ich diesem Woment ein wohlberechtigtes Interesse bei, wie die leiden folgenden, vielleicht möglichen Grenzfülle zeigen mögen. Peronaeus longus inseriert allein am Metatarsus. Tibialis allein am Kuneiforme: Bei Kontraktion beider Muskel wird das Kuneiforme hochgezogen. das Köpfchen des Metatarsale abwärts gedreht, also eine Terstärkung des Fußgewölbes in günstigster Weise bewirkt. Bei umgekehrtem. Ferhulten der Sehnen tritt auch die entgegengesetzte Wirkung ein. das Fulggewölbe wird abgeflacht. Vielleicht wäre es wertvoll, in dieser Hinsicht pathologisch-anatomische Lntersuchungen an Hohl- und Senkfül3en zu machen. Da in der Regel der stärkere Teil der Tibialissehne zum Kuneiforme zieht und der stärkere Teil der Peronaeussehne sich am Metatarsale anheftet. so wirkt der Tibialis bei Gegenwirkung des Peronneus longus wohl meist verstärkend auf das Fußgewölbe. Da aber die Bewegung in den besagten Gelenken ziemlich beschränkt ist, so tritt diese Wirkung bei gesunden Füßen äuBerlich kium in Erscheinung, sie geht in der Aufwärtsbewegung des ganzen inneren Fußrandes, die ebenfalls eine Folge der Arbeit des Tibialis ist. bei oberflächlicher Betrachtung verloren. In dem Gefüge des Fuljgewölbes jedoch wirkt sie als potentielle Energie einer Abflachung entgegeu. - Die Vermehrung oder auch nur Erhaltung des normalen Fußgewölbes durch die Tätigkeit des Tibialis anticus wird auch von anderen futoren angreführt. wenn auch zum Teil in anderer Weise erkliirt. So sagt Ernst Müller: .. Luter normalen Verhältnissen liegt die Sehme der Konvexität des Fuligewölbes, durch das Ligamentum cruciatum gehalten, straff an und hilft mit, wie die Kette an einer Kettenbrïcke, das Gewölbe hochzuhalten. - Gibt das Ligament nach, so verliert das Fußgewölbe einen der Faktoren, die es hochhalten." Giani fand. daß die Adduktionswirkung des Tibialis anticus nicht immer gleichmäßig stark ausgebildet ist und mitunter ganz fehlen kann. Wenn ein Pes planus vorhanden war, fehlte die Adduktionswirkung vollständig. Ẍach Cntersuchungen von Biesalski fand sich beim Plattfub sogar eine abduzierende Wirkung. Giani kommt zu dem Schluß, daß die fehlende Adduktionswirkung des Tibialis anticus ein die Plattfußbildung begünstigendes Moment sei, umgekehrt also der Tibialis, der in $\mathbf{4 5 \%}$ der untersuchten Fälle starke doppelseitige Adduktions- 
wirking hatte, der Abflaching der Fußsohle entgegenarbeitet. Anders als bei Müller wird hier in der Gegenwirkung gegen die Valgität des Fußes ein fïr die Vermehrung des Fußgewölbes günstiges Moment gesehen. Leider ist in der Arbeit nicht angegeben, ob nicht bei starker Adduktionskraft des Tibialis. zumal bei einseitiger, sich auf dieser Seite eine stärker gewölbte Planta pedis gefunden hat. Wir hätten somit als Wirkungsweise des Tibialis anticus: Adduktion. Supination, Dorsalflexion und Beeinflussung des Fußgewölbes: meist im sinne einer Verstärkung. Rekonstruiert man seine Tätigkeit aus den Ausfallssymptomen bei isolierter Lähmung dieses Muskels, so zeigt sich, daß seine dorsalflektierende Kraft in manchen Füllen gegenüber seiner Tätigkeit als Adduktor und Supinator schr zurücktritt: es war im Laufe der Jahre zu hochgradigem Pes plano valgus gekommen mit nur geringer Neigung zu Spitzfußstellung. Ich hatte Gelegenheit, mehrere derartige Fille zu beobachten. Waren die langen Zehenstrecker ebenfalls mehr oder weniger paretisch, so war die Equinusstellung vich hochgradiger.

Von den langen Fußmuskeln bleiben num noch die Zehenbeuger und Zehenstrecker ibrig. Bei ihnen hann ich mich anf einige allgemeine Daten beschrïnken; ihre Wirkung auf die eigentlichen Fulbgelenke erbellt aus dem bisher Gesagten zur Geniige. Weitgehendste Detaillierung findet sich in dem großen Werk von Duchenne, das schon mehrfach zitiert wurde. Als Fußheber fungieren Extensor hallucis longus und Extensor digitorum longus. Letzterer hebt gleichzeitig den äußeren Fußrand und bringt den Fuß in Valgusstellung, er flacht das Gewolbe der Planta pedis ab, indem er den Vorderfub im Chopart und Vorchopart gegen den Linterschenkel streckt und den lateralen Fußrand im Talokruralgelenk auswärts rollt. Seine abflachende Wirkung kommt dann besonders zur Geltung. wenn seine Sehne sich durch Lockerung der Ligamenta cruciata kutissenartig vom FuBrïcken abheben kann. Der Extensor hallucis longus iibt nach $D$ uchenne eine leichte adduzierende Wirkung auf den Fuß aus. Die langen Zehenbeuger bewirken neben der Senkung des Fulses auch eine plantare Beugung im Lisfranc. Vorchopart und Chopart und dadurch eine Vermehrung des Fußgewölles. Der Flexor digitorum longus zieht außerdem mit großer Kraft den vorderen lateralen Fußrand abwärts und adduziert ihn und prebt dadurch die mittlere Partie des medialen Randes: Navikulare und Kuneiformia I und II dorsalwärts. Der Flexor hallucis longus sucht wie eine Sehne den Bogen des inneren Fußrandes zu rerkürzen und dadurch zu erhöhen. - Angliedern möchte ich hier auch die kurzen Muskeln des Fußes. Die Muskeln der Fubsohle. die denen des Dorsums an Wasse um ein Vielfaches ïberlegen sind, vermögen infolge ihrer Lagerung zum größten Teil zur Erhaltung oder gar Erhöhung der Fußwölbung beizutragen. Dies gilt insbesondere für den Flexor digitonum brevis, Flexor hallucis brevis, Quadratus plantae und das Caput obliquum des Adductor hallucis. Die entsprechenden Antagonisten auf dem Dorsum sind die meist schwach entwickelten kurzen Zehenstrecker.

Die häufig zu beobachtende Klauenstellung der Zehen beim Spitzhohlfuß läßt auch die Frage nach der Zehenbewegung und die Zerlegung derselben in ihre Komponenten interessant und beachtenswert erscheinen. Ich verweise auch hier wieder auf die Arbeit von Duchenne, da näheres Eingehen weit über den Rahmen dieses Aufsatzes hinausfällt. Erwähnen muß ich nur, daß 
schon allein bei Kontraktion der langen Zehenstrecker Klauenstellung eintritt und diese durch gleichzeitige Aktion der langen Beuger noch vermehrt wird. Also auch hier wieder durch synchrone Funktionsäußerung die zu beobachtende fehlerhafte Zehenhaltung zustande kommt. Kompliziert und modifiziert wird dieser Bewegungsvorgang natürlich durch den Einfluß der anderen kleinen Zehenmuskel, wie kurze Beuger und Strecker, Lumbrikales, Interonsei u. a. m.

Zweck der vorstehenden Zeilen war, nachzuweisen und zu zeigen, daßs von der gesamten auf die FuBgelenke wirkenden Muskelenergie der unstreitig größte Prozentsatz in dem Sinne wirkt, daß der Ful3 in sipitzfußstellung tritt und eine Vermehrung des Fußgewölbes stathat. In gleicher Weise sagt auch Duncker in seiner Arbeit. ,.daß in der tbertreibung der lokomotorischen Funktion des Fußes, d. h. in Anspamung aller Fußmuskeln bei extremer Spitzfußstellung die Bedingungen für die Entstehung eines Hohlfußes gegeben sind."

Beim Gesunden ist die Kräfteverteilung dieses Muskelkomplexes so. daß sie im Verein mit den unterstützenden Bändern und dem natürlichen Wachstum der Knochen die normale Haltung und Form des menschlichen Fubes zu bewahren imstande ist. Dies geschieht auch trotz vielfach einwirkender milstaltender Kräfte. So wird z. B. durch den Druck der Körperlast auf den mit der Sohle auftretenden Fuß eine Abflachung der Fußwölbung intendiert. . Ta, es scheint geradezu, daß solche Kräfte notwendig sind. Man hann nämlich benbachten, daß sich die im übrigen gesunden Fïße eines durch andere Erkrankung für längere Zeit Bettlïgerigen gern in einen leichten Grad kontrakter Spitzfußstellung begeben, auch dann wohl. wenn durch Seitenlagerung der vielfach beschuldigte Druck der Bettdecke ausgeschaltet ist. Ich hatte Gelegenheit, im Felde hei Soldaten. die infolge ihrer Verwundung dauernde gleichmäßige Seitenlage einnehmen mulsten, diese Feststellung zu machen. Das tonische Muskelgleichgewicht am Fuße ist eben derart, daß es den Ful in eine leichte Spitzfuß- und Varusstellung bringt.

Die Erfahrung lehrt, daß die Fulggestaltung in höchstem Waße ron dem Zusammenarbeiten der Fuß-[nterschenkelmuskel abhängig ist. Beispiele dafür gibt es genug. Ich erinnere ror allem an die Fußveränderungen. Wenn durch Poliomyelitis anterior ein oder mehrere Muskeln gelähmt sind. Die Kralft der zum Teil antagonistisch wirkenden gesunden Muskeln und die Inanspruchnahme des Fußes beim Gehen üben hier in mannigfachster Weise ihre deletäre Wirkung aus. Von diesem Gesichtspunkte aus versteht man auch den Satz Duchennes: :Es ist besser, wenn man alle Muskel. die den FuB gegen den Unterschenkel bewegen. verloren hat, als wenn man davon eine gewirse Zahl behält.:

Die Beantwortung der Frage, warum gerade die drei Typen des Equinus. Varus und Exkavatus vorherrschend sind, ergibt sich ohne Berücksichtigung der in der Muskulatur selbst sich vorfindenden Veränderungen aus dem bisher Festgestellten von selbst. Erhöhtes Auswirken eines oder mehrerer Muskeln oder fast aller mit leichten, herdförmig zerstreuten Lühmungsbezirken mub in der Mehrzahl der Fälle zu dem Bilde einer der drei Deformitäten und ihren Kombinationen führen. Die Topographie der Zellsäulen der Lirsprungszonen für die motorischen Nervenfasern in den Forderhörnern ergibt, nach den einzelnen 
Tuskeln abgegrenzt, die inmerhin bemerkenswerte Tatsache, daß die Zellsäulen für die Muskeln, deren Funktion eine plantare Einstellung des Fußes und Vermehrung seiner Wölbung mit sich bringt, weiter kaudalwärts herabreichen und weniger hoch beginnen als jene Zellsïulen, aus denen die Extensoren der Zehen und der Tibialis anticus mit seiner zweideutigen Tätigkeit ihren Crsprung nehmen. Die im untersten Ende des Rückenmarks sich abspielende Bildungshemmung trifft also in quantitativer Hinsicht die FuBsenker, -adduktoren, und -verstärker des Gewolbes am meisten. Sach Villiger haben die Ursprungsbezirke folgende Ausdehnung: Tibialis anticus: L. 4 bis Mitte L. 5 . - Extensor digit. 1. - Extensor halluc. 1. - Extensor halluce brevis: Mitte L. 4 bis Mitte S. 1. - Extensor digit. brevis: Mitte L. 4 bis Ende S. 1. - Peronaei : L. 5 bis Ende S. 1. - Soleus: Mitte L. 4 bis Mitte \$. 2. - Gastroknemius: Witte L. 4 bis Ende S. 2. - Tibialis posticus: L. 5 bis Mitte S. 2. - Flexor hallue. 1.: L. 5 bis Ende $\$$. 2. - Flexor digit. 1.: L. 5 bis Nitte \$. 3. - Flexor digit. brevis: L. 5 bis Finde $S$. 1. - Flexor hallue brevis: Mitte L. 5 bis Ende S. 2. - Adcluctor halluc.: S. 1 bis Ende S. 2. - Quadratus plantae: $\$$. 1 bis Ende S. 2. Die Angalen in dem Buche von Bing sind fïr meine Auffassung noch günstiger insofern. als hier die Ursprungszonen für die kurzen und langen Zehenstrecker noch mehr kranialwärts. schon im Anfang von L. 4. beginnen. Das Symptom der Herabsetzung der Toleranzgrenze wird also bei diesen im allgemeinen ein geringeres Gebiet beherrschen als etwa bei den tief herabreichenden Kernsäulen für Trizeps, Zehenbeuger und Tibialis posticus.

Wie die Veränderungen in einem Huskel sind, der von $\mathrm{H}_{y}$ perreflexie und Hypertonie behersscht wird, ist ausführlich in Arbeiten von Jamin und von Förster beschrieben. Förster beschränkt sich zwar in der Hauptsache auf jene Fälle, da reine Pyramidenläsion (auch in der Cortex cerebri) die spastischen Eischeinungen hervorrief. Aber wir dürfen für unsere erkrnnkten Muskehn die gleichen Vorgänge gelten lassen. Die Verschiedenheit der zentralen Lüsion. die in ihrer Auswirkung die gleiche ist, äußert sich in ihren Folgen für die peripherwärts won ihr abhängigen Organe (Muskeln) in der gleichen Weise. Der anfangs nur leicht spastische Zustand der Muskeln, dessen Grad durch aktive Bewegungsanstrengung noch erhöht wird, erfährt im Laufe der . Jahre durch mannigfache Einflüsse, wie sie oben geschildert wurden, eine imner größere Steigerung und führt zu einer zunehmenden Kontraktur der befallenen Iurkeln. In diesen Schrumpfungsprozessen der Muskulatur (in Muskeln. die durch Ausfall oder starke Schwïchung ihrer Antagonisten in Kontraktur geraten, und in Muskeln, die infolge der Hypertonie und Hyperreflexie sich in Duuerkontraktur befinden) haben wir ein sekundäres Moment zur Erklärung der langsan. progredienten FuBdeformitäten bei Spina bifida occulta.

Nach Förster sind bei spastischer Reizkontraktur alle Muskeln eines Gliedes mehr oder weniger gleichmäßig gespannt, speziell sollen die antagonistischen Muskelgruppen den gleichen Spannungsgrad zeigen. Die Ausbildung der Kontrakturstellung wäre also in diesen Fällen von der zufälligen Lagerung der Glieder und dem längeren Verweilen in dieser Stellung abhängig. Förster konnte Kontrakturen nach tberwindung durch mehrtägige Fixation in gegensinnige verwandeln. Bti Besprechung der pathologischen Hohlfußbildung ïu(Bert I) uncker die Meinung, daß in diesen Fällen die am Zentral- 
orgun angreifende Lüsion pathologisch-anatomisch nicht eng begrenzt sein dürfe, sondern mehr diffuser Natur wäre und die Muskelzentren der gesimten unteren Extremität annähernd gleichmäßig irritiere. Er stellt sich damit in einen direkten Gegensatz zu Förster, der übrigens selbst seine Ausicht erschüttert, wenn er später erwähnt. daß die Plantarflektoren an sich mehr zu Kontrakturen neigten als die Dorsalflexoren. Tch möchte eher der bei Förster angefuihrten Frklärung von Monakows beipflichten, daß der an Volumen iiberwiegende Muskel auch bei Kontrakturen das Ubergewicht gewinnt und so die Stellung des kontrakten Gliedes bestimmt, und diese dahin modifizieren, daß bei gleichmäßigem Reizzustand aller Muskeln eines Gliedes diejenige Stellung eingenommen wird, in der die Endpunkte aller in Betracht kommenden Muskeln möglichst einander genähert sind. In diesem Zustande eines labilen Gleichgewichtes kann nun durch das Hinzukommen eines Plus nach der einen oder anderen Seite (durch Lagerung, Druck der Bettdecke usw.) eine Stellungsänderung eintreten und bei längerem Verweilen in dieser Haltung sich eine Kontrakturstellung ausbilden. Mit solchen ideal gedachten, absolut gleichmäBigen Reizzustänclen haben wir es nun bei dem Bilde der Spina bifida occulta wohl nur in den allerseltensten Fällen zu tun. Die einen Muskelgruppen sind mehr, die anderen weniger betroffen, sodaß nun die Kontrakturstellung ron dem Lnterschied in dem Grade der Spannung der einzelnen Muskelgruppen abhängig ist. Ein Moment. wie es Förster auch für die ,Ausfallskontrakturen" geltend macht. Nur ist hier nicht ein Ausfall auf der einen Seite, sondern ein Plus auf der anderen.

D) a wir festgestellt haben, daß die...Mittelstellung” des Fußes ein leichter Equino varus ist und daß diejenigen Muskeln, die im Sinne der Adduktion, Plantarfexion, Exkavation und Supination tätig sind, von der den Tonus erhöhenden S̈chädigung am Mark in erster Linie getroffen werden. so wird es ohne weiteres klar. daß die Mehrzahl der zu beobachtenden FuBdeformitaten bei der Śpina bifida occulta eine Kombination oder Tariation einer oder aller drei Typen des Equinus, des Farus und des Exkaratus darstellen muB.

Als direkte Folge dieser Muskelveründerungen bleiben noch die L'mformungen am Fußskelett zu besprechen. Wemn C'ramer die Entstehung des Pes plano valgus vornehmlich in einer pronierenden timlegung des inneren FuBrandes bei abnormen Bewegungen des Navikulare und Kalkaneus erkennt und bei seitlichen Ansichten fand, daß Navikulare und Kuboid sich deckten. so haben wir bei unseren Fußdeformitäten, die in weitaus der größten Zahl mit einer wechselnden Vermehrung der Fußwölbung verkniiptt sind, eine Cnterwärtsrollung des änßeren Fußrandes, die sich bei seitlichen Aufnahmen daran zu erkennen gibt, daß die Knochenreihe: Kalkaneus und Kuboid der Knochenreihe: Talus, Navikulare und Kuneiformia unterlagert zu sein scheint. In vielen: anch den weniger hochgradigen Fällen war auf der tibio-fibulären Röntgenaufnahme der Crelenkspalt zwischen Kuneiforme III - Navibulare einerseits und Kuboideum andererseits in ganzer Länge zu sehen, ohne von 
den Knochen der medialen Längshälfte (Straßer) ̈̈berdeckt zu sein. In einem Falle überlagerten sich die beiden Knochenreihen bei der dorso-plantaren Aufnahme fast vollständig! In dem gleichen Bilde lagen die proximalen Finden der Metatarsalien statt nebeneinander ebenfalls sich teilweise deckend übereimander. während die Knochen selbst fächerförmig auseinanderstrahlten. Man könnte ïber sie bei Metatarsale $V$ anfangend wie iiber eine Wendeltreppe emporsteigen, deren Achse im Lisfranc liegt; doch wäre der Aufstieg gefährlich. da alle Stufen nach der Peripherie hin sich bis zum Boden senken, die oberste also, das Metatarsale I, steil von der Höhe des Fußgewölbes nach dem Boden niederreicht. Wir haben hier das Bild der von lateral nach medial ansteigenden plantaren Einstellung der Metatarsalien, die sich nach außen in einer gewaltigen Vermehrung der Wölbung des inneren Fußrandes dokumentiert. (Der Entstehungsmechanismus dürfte im vorliegenden Fall vielleicht ein Beispiel abgeben fïr jenen Grenzfall in den Insertionsanomalien der Peroneus- und Tibialissehne, da ersterer nur am Yetatarsus und letzterer nur am Navikulare sich anheftet.) Die Veränderungen in der Lage der Knochen zueinander bleibt nicht ohne Folgen für die Gestaltung der Knochen selbst. Die Gelenkfliichen formen sich um, vergrößern sich. schleifen sich aus, werden entsprechend geringerer Funtionsbreite kleiner, zeigen Veründerungen in der mannigfachsten Art, die alle zu beschreiben unmöglich ist, die sich aber zwanglos aus der veräuderten Funktion herleiten lassen. Ganz so verhält es sich mit den Umformungen im Aufbau der Knochen selbst. Ich möchte sagen, jede Deformität hat entsprechend der Individualität ihrer Nerven- und Muskelerkrankung auch ihre, ihr allein eigentümliche Knochendeformitït. Je früher die Umgestaltung des Fußes begann, um so deutlicher sind auch die Änderungen in der Form und inneren Struktur der einzelnen Knochen. während bei den spät entstandenen Mißbildungen diese vornehmlich in den Gelenkstellungen ihren Sitz haben. Wachsender Knochen paßt sich schneller und ausgiebiger den Forderungen der Funktion an als solcher, der das Wachstum beendet hat oder doch dieser Zeit nahe steht (Konf. Wolff, Roux).

DaB auch die Gelenkbänder, Faszien. die umgebenden Weichteile und selbst die Haut durch nutritive Schrumpfung und Anpassung an die veründerte Stellung zur Fixation derselben beitragen, ist selbstverständlich. Nur ein Faszienblatt bedarf noch der Erwähnung, da es von manchen als selbstïndiger Fiktor beim Zustandekommen eines Hohlfules beschuldigt wird. Die Aponeurosis plantaris soll durch entzïndliche Prozesse - analog dem Vorgang bei der Dupuytrenschen Kontraktur - sich verkürzen und zur Verstärkung der Höhlung der Planta pedis führen. Die Möglichkeit einer solchen Fasziitis ist nicht zu leugnen; doch ist ihre Schrumpfung bei unseren Deformitäten rein als sekundär aufzufassen, auch dann. wenn sie als derber, sehr fester Streifen dem Ausgleich der Fußwölbung einen äußerst energischen Widerstand entgegenstellt. Die histologische Untersuchung einer kontrakten und deshalb exstirpierten Plantarfaszie in einem Falle. da wegen vorhergehender allerdings geringer Schmerzhaftigkeit der Gedanke an einen lokalen entzïndlichen Vorgang diskutabel war, ergab: ..Um die Gefäße der Faszie finden sich mantelartig entzündliche, zellige Infiltrate ohne spezifischen Charakter. An den ïbrigen Abschnitten der Faszie sind keine Veründerungen feststellbar" (Path. 
Institut. Prosektor Dr. Frank). Also auch wohl nur sekundäre Schrumpfungserscheinung.

In den pathologischen Prozessen, die ihren Sitz in der Muskulatur haben und durch die gestorte Innervation bedingt sind. haben wir eine weitere Crsache für das Aufteten einer progredienten Fußdeformität. Indem es zuschrumpfungen in den Muskeln und zunehmenden sichädigungen durch t'berdehnung kommt, wird die fehlerhafte Haltung des Fußes, die ursprünglich nurdurch die störung im Muskelgleichgewicht bedingt war, verstärkt. Dio in ihrer Einwirkung nun verlängerte und vermehrtefalsche Funktion zicht entsprechende Lmwandlungen in den stüzgeweben nach sich. Aus der intermittierenden fehlerhaften Haltung ist eine permanente Stellungsanomalie geworden, die infolge der dauernd einwirkenden Störungen sich mehr und mehr ausbildet. Wir haben das geschlossene Bild einer progredienten Deformitä ror uns.

Das Verhalten ron Muskulatur, Knocken, Faszien usu, gibt uns weitere Winke beim Suchen nach einer rationellen Therapie. Hier muB von Fall zu Fall entschieden werden. Es gilt die Störung im Muskelgleichgewicht, soweit sie nicht durch die Operation in loco beseitigt worden ist. röllig auszugleichen. Die Entfernung einer Fessel und eines Fettumors mag die Toleranzgrenze der Norm näherbringen, in speziellen Fällen, bei denen es sich um manifeste Drucklähmungen und trisfallserscheinungen infolge Abknickung usw. durch Arretierung handelt, anch nicht allzu lange bestehende Sichädigungen in lfark heilen. - es bleiben doch fast immer noch grobe Defekte in der Tätigkeit der Muskeln. die nur mehr durch Operationen an den Muskeln selbst vermindert werden kömnen. Hier öfnet sich für alle Arten von sehnenoperationen: Verlängenungen. Verkïrzungen. Verlagerungen. Ausschaltung usw. ein grobes: Gebiet. Mehr noch und interessinter als bei der Poliomyelitis anterior. da der zu reparierende Mechanismus viel ausgedehnter und in seiner störuny komplizierter ist. Nicoladoni weint in seiner Arbeit ïber den Pes calcaneus auf diese Art der Therapie hin. indem er bei einem Fall von Hackenhohlfuls den Vorschlag macht. die gebrachstiichtigen Peronaen auf die Achillessehne zu verpflanzen. Glaul, aber nicht recht an einen praktischen Erfoly, da er den Vorschlag als :, mehr akademischer Art" bezeichnet. Heute gehören die Erfolge der Sehnenplastiken namentlich unter Berïcksichtigung der von Biesalski angegebenen Gesichtspunkte der physiologischen Wertung und der möglichsten Erhaltung des Gleitgewebes der Sehnen (S̈cheidenauswechslung) mit zu den schōnsten einer operativen Orthopädie. Bei Kindern wird man sich im allgemeinen mit diesen Eingriffen begniigen kömnen, wenn die Veränderungen am skelett nicht zu hochgradig sind. Wird dafür Sorge getragen (durch Gipsverbände. Schienen. systematische L'bungen). daß der Fuß nicht wieder in die fehlerhafte Stellung zurückfedert, so kann unter der veränderten. der Norm genïherten Funktion eine Rückbildung der Knochenmißstaltung eintreten. Bei älteren Individuen und auch bei Kindern. wenn die Knochendeformität sehr hochgradig ist, sind Eingriffe am skelett nicht zu umgehen. Keilförmige Querresektionen nit einer Basis dorsalwärts und lateralwärts kämen bei stärksten Hohlfüßen in Betracht. Bei einem 24jährigen Mann, der 
an hochgradigstem Spitzhohlfuß litt und das Bein seit Jahren nicht mehr zum Gehen grebruchen komnte, ermöglichte dieser Fingriff allein die" Wiederhersteilung fast normalen Gehvermögens. Immerhin ist diese Operation eine verstïmmelnde und wird man Bedenken tragen, sie bei Kindern - auch mit -tiirker verkriippelten Fïßen - in Anwendung zu bringen. Der Sekundiararzt unerer dbteilung. Dr. Koenen, machte in einem solchen Falle bei einer Tugendlichen eine einfache QuerdurchmeiBelung der mittleren Fulbwurzel, korrigierte nun mit Leichtigkeit die Hohlfußbildung und erzielte damit eine. an therkorrektur grenzende Stellungsbesserung. Dieser Fingriff ist wenig schwer, gar nicht verstïmmelnd und verspricht, soweit man auf einen einzelnen Fall bauen darf. einen recht guten Erfolg. Bei Hackenhohlfüßen diurfte auch ein Eingriff nach Pürckhauer aweckmüßig sein.

In lezug auf die Operationen am Fuß, sei es Muskel oder Sehne oder Knochen oder Faszie oder Haut, nuB es vor allem heiBen: Individualisieren, nicht schematisieren! Gerade wie ein Maler, wenn er ein wertvolles Werk schaffen will, nicht nach Schablone arbeiten darf, sondern aus sich sellsit schöpfen muB, aus seinen Fähigkeiten heraussuchen muß, wie er am besten eine in ihm ruhende Idee zur Anschaung zu bringen vermag, und wie derjenige der größte Meister ist, der am vollendetsten seine Idee darzustellen vermag und dabei ein guter Meister ist, wenn seine Idee gut und veredelnd ist, so muB sich auch der jeweils richtigste Gang einer (jperation aus der jeweils besten, das erwïnschte Ziel darstellenden Idee und dem hesten Vermögen des schiffenden (operierenden) Meisters ergeben! Künstler - nicht Techniker!

\section{Zusammenlassung.}

Spina bifida occulta int a priori eine Mißbildung. die (in bezug auf vorliegende Fiille) ihren sitz im untersten Rückenmark hat. Sie geht vor sich in den ersten uterinen Lebenswochen, wenn der Abschluß der Yedullarrimne zum Vedullarrohr gestört ist, und bleibt nach Ablauf dieser Periode als solche stationär. Die große Selbständigkeit der sensiblen, hinteren Wurzeln in ihrer Entwicklung garantiert das relativ seltene Versagen dieser Komponente. Aus dem klinischen Bild der Sipina bifida occulta ergibt sich, daß die Störung vornehmlich eine Erhöhung der Reizbarkeit im Reflex- und Tomusapparan mit sich bringt. Nebenter finden sich auch reine Ausfallsherde. die zu disseminierter Lähmungsbezirken in der Mruskulatur führen. Der Conus medullaris zeigt oft an der posterioren Fläche atypische Fesselung durch Verwachsungen. die sich mitunter bis zur Hiatunterfläche fortsetzen, oder ist von einer Mischgeschwulst: einem Myofibrolipom überlagert. Geschwulst wie Fessel vermögen durch Zerrung oder Druck zu fortschreitender Schädigung des Marks zu führen. Die Symptome sind aber nur in wenigen Fällen direkt beweisend für eine solche tiefgreifende Schädigung. Trotzdem jst eine Einwirkung beider Faktoren nicht zu leugnen. Im Verein mit den Wachstumsdifferenzen des gesunden und des dysplastischen Gewebes bewirken sie eine weitere Herabsetzung der Toleranzgrenze des rezipierend-regulatorischen Apparates. (Es bleibt beim Initialstadium der Markschädigung. das auch bei andern von außen an das Mark herantretenden Schädigungen in einem Reizzustand besteht.) Muskulatur, 
Knochen usw. entwickeln sich im fötalen Iteben unabhängig ron der Funktion ans innerer Wachstunsenergie der Zellen heraus. Erst später wird die Einwirkung des funktionellen Reizes zur Erhaltung der Organe und ihrer Formen mehr und mehr notwendig. Unter besonderen Verhïltnissen kann schon in utero das funktionelle Reizleben die der Zelle innewohnende Gestaltungskraft zurückdrängen und ron sich aus Form und Beschaffenheit der ron ihm abhängigen Gewebe bedingen. Im allgemeinen tritt erst nach der Geburt die Einwirkung der Vollziehung der Funktion auf die Gestaltung der Glieder in den Vordergrund. Zeiten erhöhter Inanspruchnahme eines Gliedes lassen den Einfluß der Funktion auf die Gestalt in gesteigertem Maße zutage treten. Da am Fuß sowohl hinsichtlich der Verteilung der Muskulatur wie der Anordnung der Gelenke die Verhältnisse zur Bildung eines Spitzhohlfußes äußerst günstig liegen und die Funktionsstörung in der Muskulatur in überwiegendem Maße nach der spastischen Seite hinneigt, so erklït es sich, daß in der Mehrzihl der Fälle es zur Bildung eines Pes equinus, Pes varus, Pes excavatus und deren Variationen und Kombinationen kommen muß. Die Veränderungen in der Muskulatur - Schrumpfung und Ủberdehnung - sind sekundärer Natur, führen aber ihrerseits zur Vervollstïndigung der Deformität. Umformungen im äußeren und inneren Knochenaufbau und gleichartige Anderungen in den Jändern, Fuszien, Gelenkkapseln usw. tragen zur Fixierung der Deformität in erster Linie bei.

Die Therapie hat zunächst die Schïdigung am Jlark zu beseitigen. I die Mißbildung im Zentralnervensystem selbst einem operativen Eingriff nicht zugängig ist, so bleibt nur die Möglichkeit der Fntfernung der von außen herantretenden Noxen: Fessel und Tumor. Dann mul sie darauf bedacht sein, das gestörte Muskelgleichgewicht — namentlich im Hinblick auf die durch sichrumpfung. Uberdehnung und spastische Zustände gestörte Funktion - wiederherzustellen. Und zuletzt endlich kommen bei starken. manifesten Knochendeformitäten ()perationen an diesen selbst und den geschrumpften Faszien in Erage. 
Abbildungen zu vorstehender Arbeit ${ }^{1}$ ).

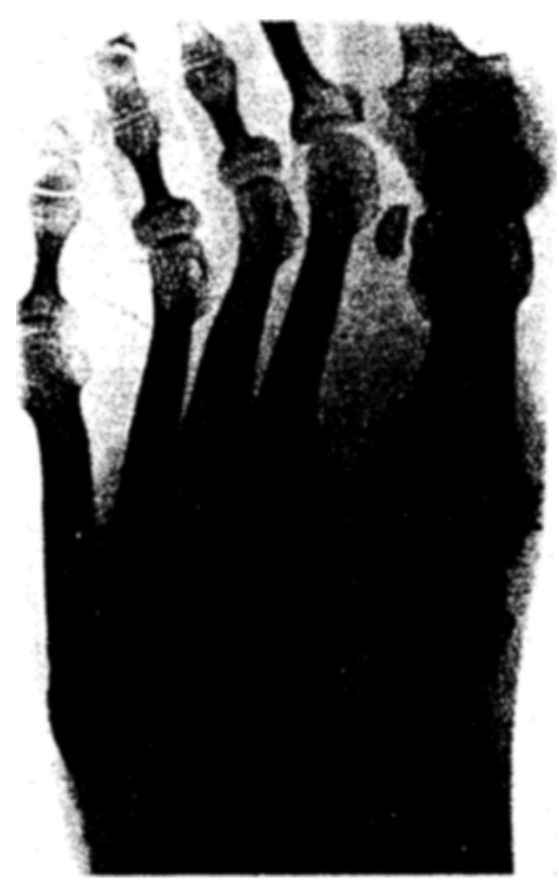

Abb. 1. Traumatischer Hohlfuß (dorsoplantar). Mediale und laterale Knochenrejho liegen nebeneinander. Starke plantare Einstellung ron Metatarsale I, welches daher verkürzt erscheint.

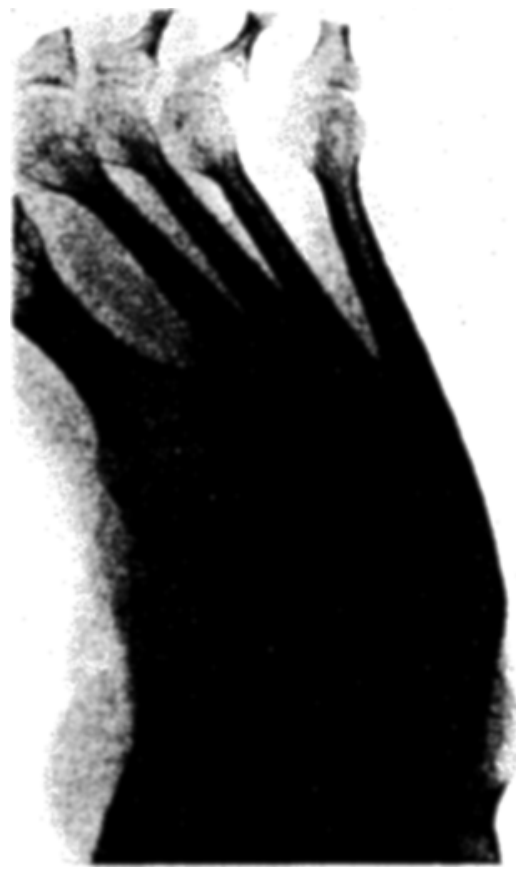

Abb. 2. Hohlfuß bei Spina bifida occulta (dorsoplantar). Wediale und laterale Knochenreihe decken sich vollstündig. Wendeltreppe der Metatarsalien. Metatarsale $I$ von der Höhe steil zum Boden ab. fallend.

1) Mit. Rücksicht auf die hohten Herstellungskosten der Reproduktionen habe ich. wenn auch schweren Herzens, von der Wiedergabe des gesamten Bildermaterials, das sehr reichhaltig ist, Abstand genommen und die Zahl auf sieben Bilder beschränkt. Ich konnte es deshalb tun, weil die Bilder - namentlich die Röntgenogramme der untersten Wirbelsäule - in ähnlicher Art sich in anderen einschlägigen Arbeiten finden, wenn es sich auch um vollständig neues Material handelte und ich der ursprünglich geplanten elektiven Zusammenstellung einen gewissen Wert beimaB. 


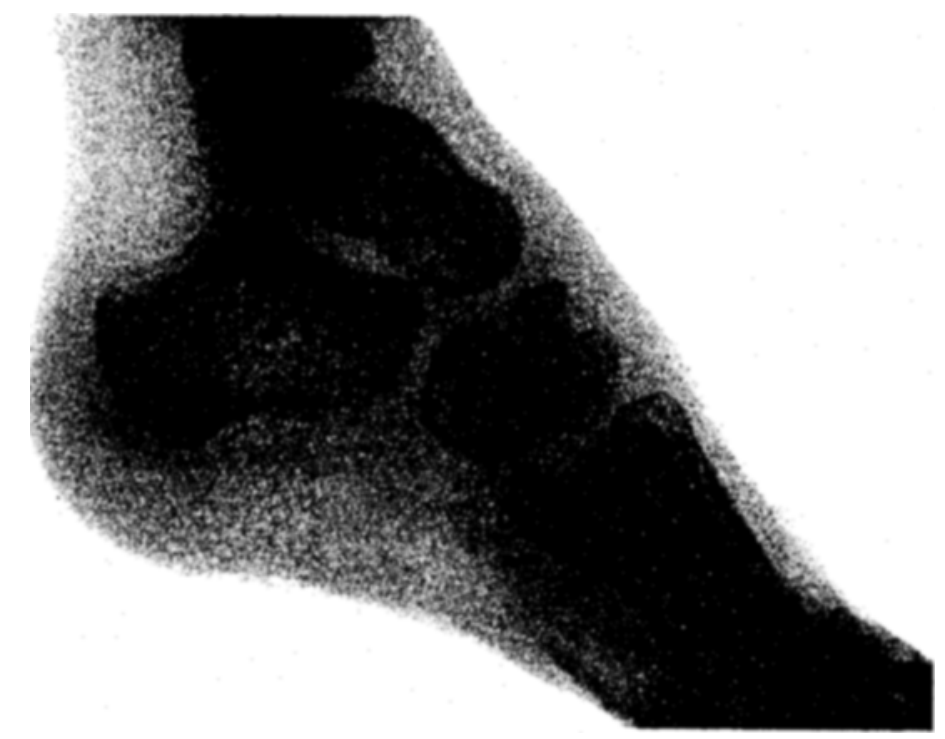

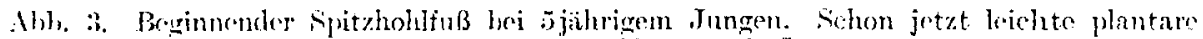
Finstrllung von Metatarsale I.

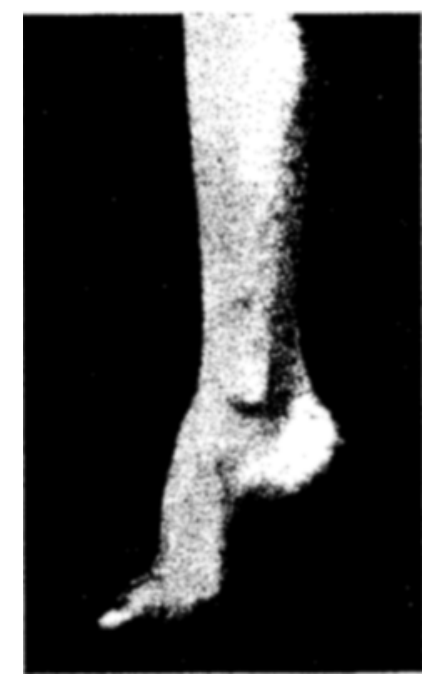

Abb. 4.

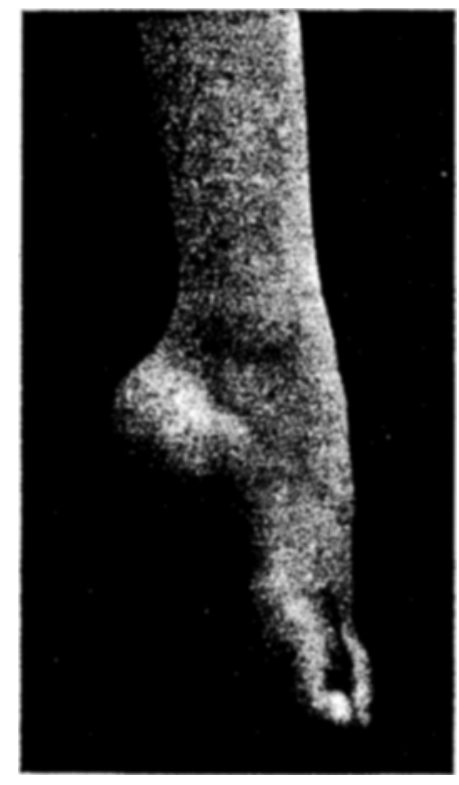

Abb. $\tilde{5}$.

Abb. 4 and 5 . Spitzhohlfïße bei sinina bifida reculta. jedoch mit dem augenfälligen I'nter. schied, daB bei 4 sämtliche II skbeln willkürlich in Aktion treten konnten, während 5 das Bild einer totalen, dehlaffen Läbmung zeigte, indes jede trophische, vasomotorisehe und semsible Störung frhlte. (Faradisch konnten leichte Zuekungen im Tibialis posticus hervorgerufen werden.) 


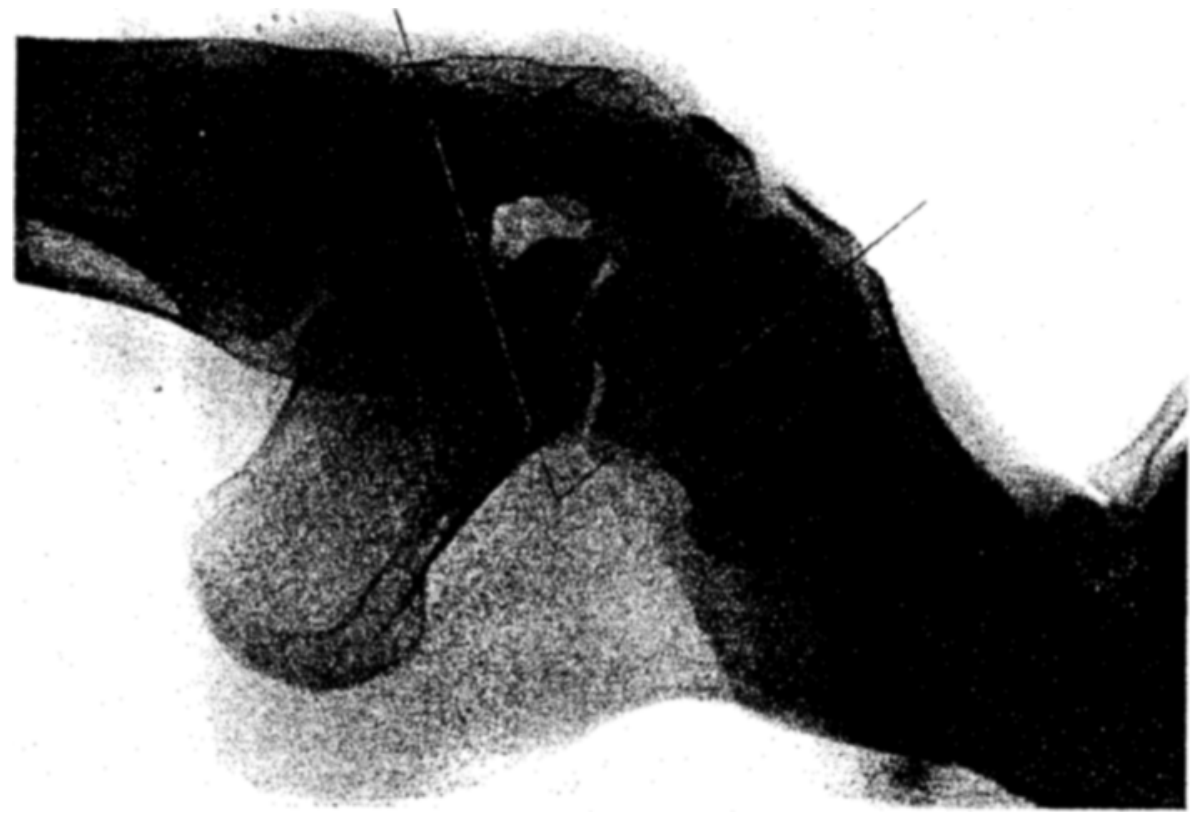

Abb. 6. Hochgradigster SpitzhohlfuB bei 24 jälırigem Mann. Beginn im sechsten Lebensjahr. Fußriicken war gegen Lnterschenkel zurückgebogen. Hebung und senkuns waren fleich Null, da dic Sohnen von Tibialis ant. und Extensor hall. longus medialwärts und die Selnen von Extensor digit. longus lateralwärts luxicrt waren und die Kontraktion diese' Huskeln nur eine fast reine Ab- resp. Adduktionsbewegung hervorrief. Selbst in diesem Falle ist das Navikulare nicht nach dem Dorsum zu subluxiert. Der Ausfall eines ganzenk Interschenkelfußmuskels war nicht nachweisbar. Die Stürung in der sensorischen Fomponente bestand in einer Herabsetzung der sohmerzempfindung am ganzen linken (es ist der rechte Fuß!) Cnterschenkel und an der Innenseite des rech ten Uherschenkcls. Der linke Fuß war wohlrestaltet. - - Keilfömige Querresektion etwa in Ausdehnung der einvezeichneten Linien brachte ein bestes kosmetisches und funktionelles Resultat. Der Gang des V. war nach Ausgleich der geringfügugen Verküzung durch Maßschuhe für Laien nicht mehr yon normalem Gang zu unterscheiden, Auch ergab sieh eine Wiederkehr der Plantardorsalflexion, wenn auch in geringem Grade. Eine Iblatio des in seiner friheren Crestalt unbrauchbaren Fußes wäre für den Patienten weniger vorteilhaft gewesen.

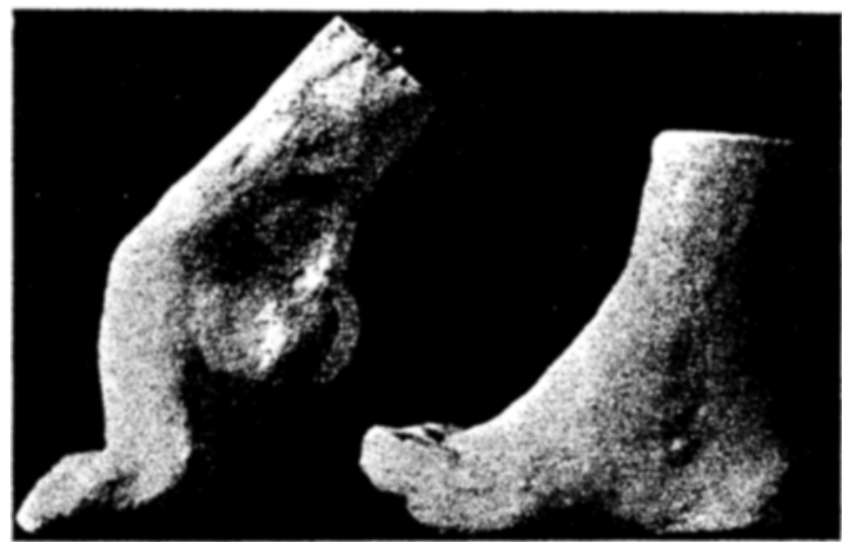

Abb. 7. Gipsmorlelle des vorerwähnten Fußes vor und nach der Operation. Auch die leichte Krallenstellung der Zehen ist ausgeglichen. Es besteht noch rnäßige üdematöse Schwellung im Bereich des durch die Operation gesetzten Traumas.

Archiv tir orthopädische und Usiall-Chirurgie. Bd. XIX. 